\title{
Inhibition and activation of enzymes. The effect of a modifier on the reaction rate and on kinetic parameters ${ }^{\star}$
}

\author{
Rui Fontes ${ }^{\star}$, João Meireles Ribeiro and Antonio Sillero \\ Instituto de Investigaciones Biomédicas Alberto Sols, UAM-CSIC, Departamento de Bioquímica, \\ Facultad de Medicina, Arzobispo Morcillo 4, E-28029 Madrid, Spain
}

Received: 3 November, 1999

Key words: enzyme activation, enzyme inhibition, enzyme kinetics, enzyme modifier, graphical presentations, $\mathrm{I}_{50}$, rapid equilibrium kinetics

\begin{abstract}
A combined analysis of enzyme inhibition and activation is presented, based on a rapid equilibrium model assumption in which one molecule of enzyme binds one molecule of substrate (S) and/or one molecule of a modifier $X$. The modifier acts as activator (essential or non-essential), as inhibitor (total or partial), or has no effect on the reaction rate $(v)$, depending on the values of the equilibrium constants, the rate constants of the limiting velocity steps, and the concentration of substrate ([S]). Different possibilities have been analyzed from an equation written to emphasize that $v=f([\mathrm{X}])$ is, in general and at a fixed [S], a hyperbolic function. Formulas for $S_{\mathrm{u}}$ (the value of [S], different from zero, at which $v$ is unaffected by the modifier) and $v_{\text {su }}(v$ at that particular [S]) were deduced. In Lineweaver-Burk plots, the straight lines related to different [X] generally cross in a point $(\mathrm{P})$ with coordinates $\left(S_{\mathrm{u}}, v_{\text {su }}\right)$. In certain cases, point $P$ is located in the first quadrant which implies that $X$ acts as activator, as inhibitor, or has no effect, depending on [S]. Furthermore, we discuss: (1) the apparent $V_{\max }$ and $K_{\mathrm{m}}$ displayed by the enzyme in different situations; (2) the degree of effect (inhibition or activation) observed at different concentrations of substrate and modifier; (3) the concept of $K_{\mathbf{e}}$, a parameter that depends on the concentration of substrate and helps to
\end{abstract}

\footnotetext{
^ Supported by grants from Dirección General de Investigación Científica y Técnica (PM95/0013 and PM98/0129, A.S.; PM97/0022, J.M.R.) and from Comunidad de Madrid (08.9/0004/98, to A.S.). R.F. was supported by a fellowship from Junta Nacional de Investigação Científica e Tecnológica (Portugal). During part of this work, J.M.R. held a postdoctoral fellowship from Consejería de Educación y Juventud, Junta de Extremadura (Spain; PRI9606B064), cofinanced by the Fondo Social Europeo.

*Present address: Serviço de Química Fisiológica, Faculdade de Medicina, Universidade do Porto, Porto, Portugal

Present address: Unidad de Bioquímica y Biología Molecular, Facultad de Medicina, Universidad de Extremadura, E-06080 Badajoz, Spain; E-mail: jribeiro@unex.es

${ }^{\circledR}$ Corresponding author: Dr. Antonio Sillero, Departamento de Bioquímica, Facultad de Medicina UAM, Arzobispo Morcillo 4, 28029 Madrid, Spain; Phone: (34 91) 397 5413; Fax: (34 91) 3975353;

e-mail: antonio.sillero@uam.es
} 
evaluate the effect of the modifier: it equals the value of $[\mathrm{X}]$ at which the increase or decrease in the reaction rate is half of that achieved at saturating [X]. Equations were deduced for the general case and for particular situations, and used to obtain computer-drawn graphs that are presented and discussed. Formulas for apparent $V_{\max }$, $K_{\mathrm{m}}$ and $K_{\mathbf{e}}$ have been written in a way making it evident that these parameters can be expressed as pondered means.

Reversible enzyme inhibition and reversible enzyme activation, imply the binding to the enzyme of a modifier (X) which affects the rate of an enzyme-catalyzed reaction. Despite the similitude between the two processes, enzyme inhibition and activation are very often discussed independently in enzymology textbooks [1-5]. Enzyme inhibition is usually extensively analyzed due to its great interest both in the study of enzyme mechanisms [6] and in pharmacological studies [7], while enzyme activation is subject of a less detailed presentation, if any at all. Yet, the generic term "modifier", comprising both the concept of inhibitor and activator, was introduced more than 40 years ago by Botts \& Morales [8], to refer to compounds, other than substrates, that specifically bind to enzymes and modify their velocity rates. A simple general scheme to describe the interactions between an enzyme $\mathrm{E}$, a substrate $\mathrm{S}$ and a modifier $\mathrm{X}$ was also presented in this classical paper. This scheme, more or less modified, although limited to the case of enzymes binding only one molecule of substrate and/or one molecule of modifier, has been reproduced in many standard textbooks or publications that discuss enzyme kinetics (Fig. 1) [1-5, 9-12].

The concept of modifier is important because, in certain conditions, a compound may act as an activator or inhibitor of an enzyme depending on the substrate concentration, and so not always there is a clear cut distinction between enzyme inhibition and enzyme activation. Actually, a kinetic analysis of the modification of the reaction rate can be undertaken without any need of prejudging the effect (activation or inhibition) of the modifier on the enzyme.

In the course of a search for new approaches to graphically visualize enzyme inhibition
[13-15] we made a systematic analysis of the relationship between rate and equilibrium constants and concentration of substrate and modifier. So far as we are aware, no such a detailed study, although in some aspects coincident with the classic paper of Frieden [16], was undertaken before. We arrived at equations that describe the dependence of reaction rate and parameters of the enzyme-catalyzed reaction on the concentrations of substrate and/or modifier. These equations were the basis for the computer-aided graphs that are presented and discussed here.

\section{GLOSSARY}

$v$ is the reaction rate (initial velocity) at specified concentrations of substrate (S) and modifier (X) $v=[\mathrm{ES}] k_{1}+[\mathrm{ESX}] k_{2}$ (Fig. 1; eqns. 2 and 9 ).

$S_{\mathrm{u}}$ is a value of [S] different from zero that, makes $v$ unaffected by changes in the value of [X] (eqn. 8).

$v_{\mathrm{xo}}, v_{\mathrm{x} \infty}$, and $v_{\mathrm{su}}$ are, respectively, the reaction rates in absence of $\mathrm{X}$ (eqn. 3), at saturating [X], and when [S] $=S_{\mathrm{u}}$ (eqn. 13).

$V_{\mu}$ is the difference between $v_{\mathrm{x} \infty}$ and $v_{\mathrm{xo}}$ (eqns. 4 and $4 \mathrm{a}$ ).

$V_{\max }$ is the initial velocity at saturating [S] and at a determined [X]; i.e. the apparent maximal velocity displayed by the enzyme at a determined [X] (eqns. 10 and 10a).

$K_{\mathrm{m}}$ is the apparent Michaelis constant at a determined [X] (eqns. 11, 11a, and 11b).

$K_{\mathrm{e}}$ is a parameter with dimensions of concentration, and its value equals [X] at which, at a determined [S], the increase or decrease in the reaction rate is half of that achieved at saturating [X] (eqns. 5, 5a, and 5b). 
$\varepsilon$ is the degree of effect of $\mathrm{X}$ on the reaction rate, i.e. the ratio $\left(v-v_{\mathrm{xo}}\right) /$ vxo (eqns. 14 and 18).

$\varepsilon_{\mathrm{So}}$ and $e_{\mathrm{S} \infty}$ are the limits to which the degree of effect of a determined [X] tends when [S] tends to zero or infinity, respectively (eqn. 19).

$E_{\sigma}$ is the difference between $e_{\mathrm{S} \infty}$ and $e_{\mathrm{so}}$ (eqn. 20).

$E_{\mathrm{t}}$ is the total concentration of enzyme.

\section{ACTIVATION AND INHIBITION}

A plausible and simple general model for interactions between an enzyme $\mathrm{E}$, a substrate $\mathrm{S}$ and a modifier $\mathrm{X}$ is represented by the scheme in Fig. 1.

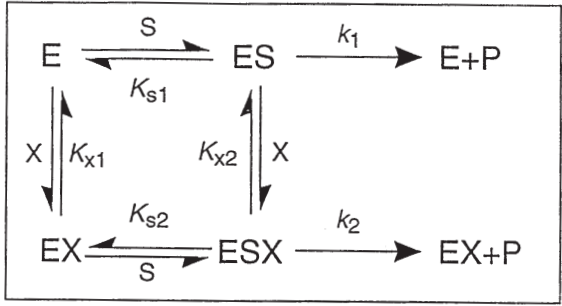

Figure 1. Scheme representing the mechanism of the enzyme-catalyzed reaction and interactions of the enzyme with a modifier $X$ and the substrate $S$.

In this model, a molecule of enzyme (E) can bind one molecule of substrate (S) and/or one molecule of modifier (X). $K_{\mathrm{s} 1}, K_{\mathrm{s} 2}, K_{\mathrm{x} 1}$ and $K_{\mathrm{x} 2}$ are the equilibrium constants for the dissociation reactions $\mathrm{ES} \leftrightarrow \mathrm{E}+\mathrm{S}, \mathrm{ESX} \leftrightarrow$ $\mathrm{EX}+\mathrm{S}, \mathrm{EX} \leftrightarrow \mathrm{E}+\mathrm{X}$ and $\mathrm{ESX} \leftrightarrow \mathrm{ES}+\mathrm{X}$, respectively. $k_{1}$ and $k_{2}$ are the rate constants for, respectively, the reactions $\mathrm{ES} \rightarrow \mathrm{E}+\mathrm{P}$ and $\mathrm{ESX} \rightarrow \mathrm{EX}+\mathrm{P}$ (product); they are related to the parameters $V_{1}$ and $V_{2}$ by the equations $V_{1}$ $=k_{1}\left[\mathrm{E}_{\mathrm{t}}\right]$ and $V_{2}=k_{2}\left[\mathrm{E}_{\mathrm{t}}\right]$. See text for other assumptions relating to the model.

In this scheme it is assumed that: (i) an equilibrium between enzyme (E), substrate (S), modifier (X), and their complexes ES, EX and ESX is almost instantly set up and maintained during the time required to measure the initial velocity; (ii) the concentrations of $\mathrm{S}$ and $\mathrm{X}$ are much higher than $\left[\mathrm{E}_{\mathrm{t}}\right]$ so that the concentrations of $\mathrm{S}$ and $\mathrm{X}$ do not change after they bind to the enzyme; (iii) the velocities of product (P) formation from the complexes ES and ESX are the velocity limiting steps in the process of transformation $\mathrm{S} \rightarrow \mathrm{P}$.

$k_{1}$ and $k_{2}$ are the rate constants for, respectively, the reactions $\mathrm{ES} \rightarrow \mathrm{E}+\mathrm{P}$ and $\mathrm{ESX} \rightarrow$ $\mathrm{EX}+\mathrm{P} . k_{1}$ and $k_{2}$ are related to two parameters, $V_{1}$ and $V_{2}$, by the following equations:

$V_{1}=k_{1}\left[\mathrm{E}_{\mathrm{t}}\right]$
$V_{2}=k_{2}\left[\mathrm{E}_{\mathrm{t}}\right]$

$\left[\mathrm{E}_{\mathrm{t}}\right]$ is the total concentration of enzyme: $\left[\mathrm{E}_{\mathrm{t}}\right]=[\mathrm{E}]+[\mathrm{ES}]+[\mathrm{EX}]+[\mathrm{ESX}]$.

$K_{\mathrm{s} 1}, K_{\mathrm{s} 2}, K_{\mathrm{x} 1}$ and $K_{\mathrm{x} 2}$ are the equilibrium constants for the dissociation reactions ES $\leftrightarrow$ $\mathrm{E}+\mathrm{S}, \mathrm{ESX} \leftrightarrow \mathrm{EX}+\mathrm{S}, \mathrm{EX} \leftrightarrow \mathrm{E}+\mathrm{X}$ and $\mathrm{ESX} \leftrightarrow$ $\mathrm{ES}+\mathrm{X}$, respectively:

$\begin{aligned} K_{\mathrm{s} 1} & =[\mathrm{E}][\mathrm{S}] /[\mathrm{ES}] \\ K_{\mathrm{s} 2} & =[\mathrm{EX}][\mathrm{S}] /[\mathrm{ESX}] \\ K_{\mathrm{x} 1} & =[\mathrm{E}][\mathrm{X}] /[\mathrm{EX}] \\ K_{\mathrm{x} 2} & =[\mathrm{ES}][\mathrm{X}] /[\mathrm{ESX}]\end{aligned}$

These four equilibrium constants are not independent. They are related by eqn. (1) and so any three of them determine the forth. Some consequences of eqn. (1) are explored in Appendix A of this paper.

$K_{\mathrm{s} 1} K_{\mathrm{x} 2}=K_{\mathrm{s} 2} K_{\mathrm{x} 1}$

In the absence of modifier, only the reactions shown in the upper part of the scheme in Fig. 1 take place, and the enzyme displays a michaelian-type kinetics with apparent values of $V_{\max }$ and $K_{\mathrm{m}}$ equal to $V_{1}$ and $K_{\mathrm{s} 1}$, respectively. In the presence of saturating concentrations of modifier, the equilibrium is almost completely displaced towards the reactions shown in the lower part of the scheme (Fig. 1); the enzyme still presents a michaelian-type kinetics, but with apparent values of $V_{\max }$ and $K_{\mathrm{m}}$ equal to $V_{2}$ and $K_{\mathrm{s} 2}$, respectively. At any 
other concentration of $\mathrm{X}$, the enzyme will display apparent values of $V_{\max }$ and $K_{\mathrm{m}}$ between $V_{1}$ and $V_{2}$, and between $K_{\mathrm{s} 1}$ and $K_{\mathrm{s} 2}$, respectively.

A compound $\mathrm{X}$ may be a modifier when its binding to the enzyme affects the apparent values of $V_{\text {max }}$ and/or $K_{\mathrm{m}}$ of the enzyme-catalyzed reaction, i.e. if $k_{1} \neq k_{2}$ and/or $K_{\mathrm{s} 1}$ $\neq K_{\mathrm{s} 2}$. As it will be discussed later, these conditions are necessary, but not sufficient for $\mathrm{X}$ to be a modifier.

In the context of this paper, one dissociation constant is said to be infinity when its value is much higher than the concentrations of S (for $K_{\mathrm{s} 1}$ or $K_{\mathrm{s} 2}$ ) or X (for $K_{\mathrm{x} 1}$ or $K_{\mathrm{x} 2}$ ) that can be used in a real assay. Similarly, a dissociation constant is said to be zero when its value is so low that concentrations of $\mathrm{S}$ or $\mathrm{X}$ just higher than $\left[\mathrm{E}_{\mathrm{t}}\right]$ almost completely saturate the enzyme. In both cases, an equilibrium is almost completely displaced in one direction, and the concentration of one or more enzyme complex(es) is almost zero (Fig. 2). Although several combinations are possible (see eqn. 1), only three pairs are biochemically relevant: (a) $[\mathrm{EX}]$ is almost zero, $\mathrm{S}$ binds to the enzyme whereas $\mathrm{X}$ has no affinity to free enzyme molecules, $K_{\mathrm{x} 1}=\infty$ and $K_{\mathrm{s} 2}=0$; (b) [ESX] is almost zero, $\mathrm{X}$ is a competitive total inhibitor, $K_{\mathrm{x} 2}=\infty$ and $K_{\mathrm{s} 2}=\infty$; and (c) [ES] is almost zero, $\mathrm{S}$ has no affinity to free enzyme molecules, but it can bind to the $\mathrm{EX}, K_{\mathrm{s} 1}=\infty$ and $K_{\mathrm{x} 2}=0$ (Fig. 2). So, it should be pointed out that, in the context of this paper, $K_{\mathrm{x} 1}=\infty$ is equivalent to $K_{\mathrm{s} 2}=0 ; K_{\mathrm{x} 2}=\infty$ is equivalent of $K_{\mathrm{s} 2}=\infty$; and $K_{\mathrm{s} 1}=\infty$ is equivalent to $K_{\mathrm{x} 2}=0$.

In agreement with the model in Fig. 1, the eqn. (2) (deduced from eqn. 9; see Appendix B) shows clearly the influence of the modifier $\mathrm{X}$ on the reaction rate at a fixed concentration of $\mathrm{S}$.

$$
v=v_{x 0}+\frac{V_{\mu}[\mathrm{X}]}{K_{e}+[\mathrm{X}]}
$$

where,

$v_{x 0}=\frac{V_{1}[\mathrm{~S}]}{K_{s 1}+[\mathrm{S}]}$

$V_{\mu}=\frac{V_{2}[\mathrm{~S}]}{K_{s 2}+[\mathrm{S}]}-\frac{V_{1}[\mathrm{~S}]}{K_{s 1}+[\mathrm{S}]}$

$K_{\varepsilon}=\frac{K_{x 1} K_{s 2}+K_{x 2}[\mathrm{~S}]}{K_{s 2}+[\mathrm{S}]}$

These equations, as all the equations in this paper, are valid when the denominators are not zero.

The value of $V_{\mu}$ in each particular enzymatic system depends on [S]. $K_{\mathrm{e}}$ has dimensions of concentration and will be discussed later in this paper. In Tables 1 and 2 , formulas for $V_{\mu}$ and $K_{\mathrm{e}}$ in particular cases are presented. According to Fontes et al. [17], eqn. (5) can also be formulated as in Table 2 (eqn. $5 \mathrm{a}$; see below).

Equation (2) shows that the plot $v$ versus [X] is, in general, a rectangular hyperbola that intercepts the vertical axis at $v=v_{\mathrm{x} 0}$, which at certain values of the parameters becomes the equation for the horizontal asymptote $v=v_{\mathrm{xo}}+$ $V_{\mu}$ or for the vertical asymptote $[\mathrm{X}]=-K_{\mathrm{e}}$. Positive values of $V_{\mu}$ indicate that, at the corresponding [S] values, the modifier acts as an activator and the form of the curve is an ascending hyperbola. Negative values of $V_{\mu}$ indicate that the modifier acts as an inhibitor and that the form of the curve is a descending hyperbola. In the limiting case in which $V_{\mu}=0$ the modifier has no effect on the reaction rate and the plot described by eqn. (2) is a straight line parallel to the horizontal axis. In Fig. 3 these and other possible aspects of the plot $v$ versus $[\mathrm{X}]$ are presented.

The sign of $V_{\mu}$ can be easily deduced if eqn. (4) is rewritten as 


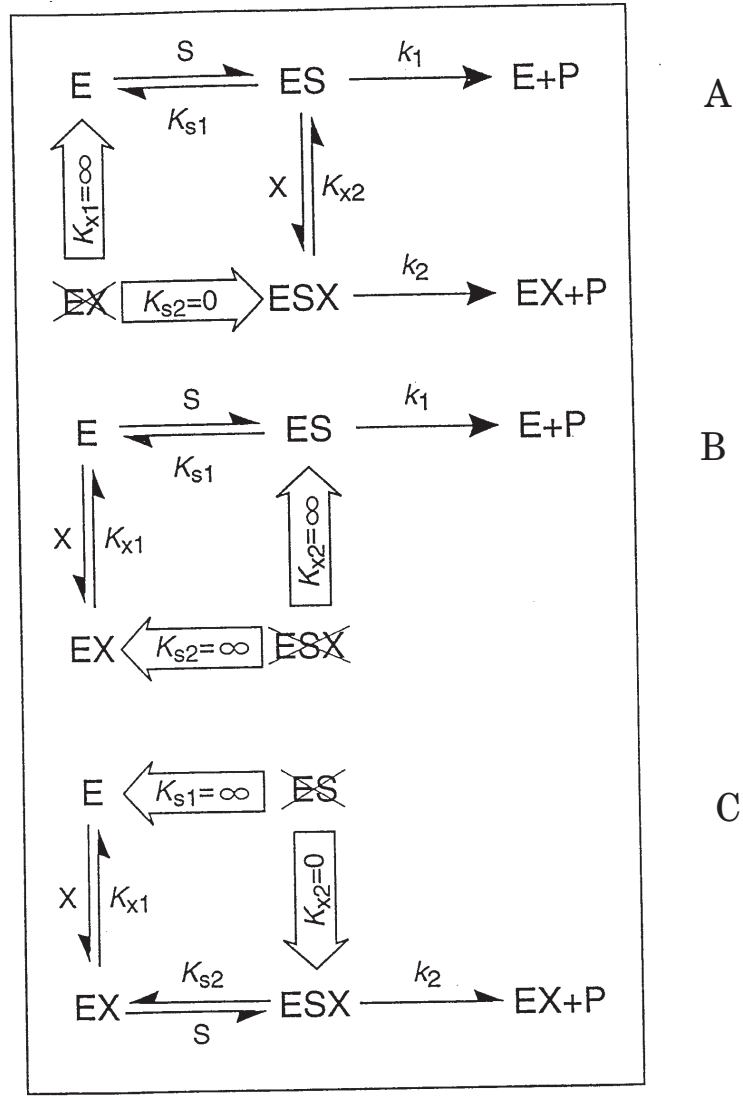

Figure 2. Particular cases of the general mechanism represented in Fig. 1. Wide arrows mean that, as indicated, the value of a specified dissociation constant equals zero or infinity, and so the equilibrium is completely displaced in one direction; the non-existing enzyme complex is crossed out.

In case $A$, X can not bind to $\mathrm{E}\left(K_{\mathrm{x} 1}=\infty\right)$, ESX can not dissociate into $\mathrm{EX}+\mathrm{S}\left(K_{\mathrm{s} 2}=0\right)$, and formation of the complex EX does not take place. In this case, the order of binding of $\mathrm{X}$ and $\mathrm{S}$ is not random, i.e. $\mathrm{S}$ binds first to the enzyme, and three possibilities can be analyzed: (A1) When the rate constant $k_{2}=0$ and so $V_{2}=0$, the increase of [X] from zero to saturation decreases both $V_{\max }$ and $K_{\mathrm{m}}$ from specified finite values $\left(V_{1}\right.$ and $\left.K_{\mathrm{s} 1}\right)$ to zero $\left(V_{2}=0\right.$ and $\left.K_{\mathrm{s} 2}=0\right)$; this is the classic uncompetitive total inhibition case. (A2) When $k_{1}=0\left(V_{1}=0\right)$, the increase of [X] from zero to saturation increases $V_{\max }$ from zero to $V_{2}$ and decreases $K_{\mathrm{m}}$ from $K_{\mathrm{s} 1}$ to zero; this is the classical essential activation case in which $\mathrm{S}$ binds first. (A3) When $k_{1}$ and $k_{2}$ are positive (both $V_{1}$ and $V_{2} \neq 0$ ), three cases can occur: ( $A 3 a$ ) if $k_{1}=k_{2}\left(V_{1}=V_{2}\right)$, the increase of [X] promotes a decrease of $K_{\mathrm{m}}$ values without any change in $V_{\max }$ values, and X is an activator at any finite [S] and has no effect at saturating [S]; $(A 3 b)$ if $k_{2}>k_{1}\left(V_{2}>V_{1}\right)$, the modifier is an activator at all concentrations of $\mathrm{S}$ due to the increase in $V_{\max }$ and decrease in $K_{\mathrm{m}}$ values; and $(A 3 c)$ if $k_{1}>k_{2}\left(V_{1}>V_{2}\right)$, the effect of $\mathrm{X}$ is more interesting because it produces contradictory effects: it decreases both $K_{\mathrm{m}}$ and $V_{\max }$, and inhibition or activation can occur depending on the concentration of substrate. In the case $B, \mathrm{X}$ can not bind to ES $\left(K_{\mathrm{x} 2}=\infty\right)$, S can not bind to $\mathrm{EX}\left(K_{\mathrm{s} 2}=\infty\right)$, and formation of the complex ESX does not take place; this is the classic competitive total inhibition case. In this case, it is better not to assume that $V_{2}=0$ but state that $V_{2}$ does not exist (because of the absence of the ESX complex). In fact, the value of $V_{\max }$ does not change when [X] changes, and always equals $V_{1}$; when the concentration of $\mathrm{X}$ increases from zero to saturation $K_{\mathrm{m}}$ increases from a finite value $\left(K_{\mathrm{s} 1}\right)$ approaching infinity $\left(K_{\mathrm{s} 2}=\infty\right)$. In case $C, \mathrm{~S}$ can not bind directly to $\mathrm{E}\left(K_{\mathrm{s} 1}=\infty\right)$ and formation of the complex ES does not take place; $\mathrm{X}$ binds first to the enzyme followed by the substrate. Moreover, the complex ESX can not dissociate into $\mathrm{ES}+\mathrm{X}\left(K_{\mathrm{x} 2}=0\right)$; this is the classic essential activation case. As in case $B$, it would be better to state that $V_{1}$ does not exist (because of the absence of the ES complex). Although $V_{\max }$ (and $v$ ) is zero when $\mathrm{X}$ is absent, when $\mathrm{X}$ is present the value of $V_{\max }$ always equals $V_{2}$ and does not change when [X] changes. When the concentration of $\mathrm{X}$ decreases from saturation and approaches zero, the $K_{\mathrm{m}}$ increases from a finite value $\left(K_{\mathrm{s} 2}\right)$ approaching infinity $\left(K_{\mathrm{s} 1}=\infty\right)$. This case, as well as case $A 2$, could also represent an ordered sequential mechanism of a bisubstrate reaction, with both $\mathrm{S}$ and $\mathrm{X}$ as substrates of the enzyme reaction. 
Table 1. Formulas for $V \mu$ and $V_{\max }$ in particular cases of the rapid equilibrium model

\begin{tabular}{|c|c|c|c|}
\hline Class & Subclass & $V_{\mu}$ & $V_{\max }$ \\
\hline \multirow[t]{6}{*}{$\begin{array}{l}V_{1} \neq 0 \\
\text { and } \\
V_{2} \neq 0\end{array}$} & more general & $\frac{V_{2}[\mathrm{~S}]}{K_{\mathrm{s} 2}+[\mathrm{S}]}-\frac{V_{1}[\mathrm{~S}]}{K_{\mathrm{s} 1}+[\mathrm{S}]}$ & \multirow[t]{4}{*}{$V_{1}+\frac{\left(V_{2}-V_{1}\right)[\mathrm{X}]}{K_{\mathrm{x} 2}+[\mathrm{X}]}$} \\
\hline & $\begin{array}{c}K_{\mathrm{x} 1}=\infty \text { and } \\
K_{\mathrm{s} 2}=0\end{array}$ & $V_{2}-\frac{V_{1}[\mathrm{~S}]}{K_{\mathrm{s1}}+[\mathrm{S}]}$ & \\
\hline & $\begin{array}{l}K_{\mathrm{s} 1}=K_{\mathrm{s} 2}=K_{\mathrm{s}} \\
K_{\mathrm{x} 1}=K_{\mathrm{x} 2}=K_{\mathrm{x}}\end{array}$ & $\frac{\left(V_{2}-V_{1}\right)[\mathrm{S}]}{K_{\mathrm{s}}+[\mathrm{S}]}$ & \\
\hline & $\begin{array}{l}V_{1} K_{\mathrm{s} 2}=V_{2} K_{\mathrm{s} 1} \\
V_{1} K_{\mathrm{x} 2}=V_{2} K_{\mathrm{x} 1}\end{array}$ & $\frac{\left(V_{2}-V_{1}\right)[\mathrm{S}]^{2}}{[\mathrm{~S}]^{2}+\left(K_{\mathrm{s} 1}+K_{\mathrm{s} 2}\right)[\mathrm{S}]+K_{\mathrm{s} 1} K_{\mathrm{s} 2}}$ & \\
\hline & $\begin{array}{l}V_{1}=V_{2}=V \\
\text { more general }\end{array}$ & $\frac{V\left(K_{\mathrm{s} 1}-K_{\mathrm{s} 2}\right)[\mathrm{S}]}{[\mathrm{S}]^{2}+\left(K_{\mathrm{s} 1}+K_{\mathrm{s} 2}\right)[\mathrm{S}]+K_{\mathrm{s} 1} K_{\mathrm{s}}}$ & \multirow[t]{2}{*}{$\bar{V}$} \\
\hline & $\begin{array}{c}V_{1}=V_{2}=V \text { and } \\
K_{\mathrm{x} 1}=\infty \text { and } \\
K_{\mathrm{s} 2}=0\end{array}$ & $\frac{V K_{\mathrm{s} 1}}{K_{\mathrm{s} 1}+[\mathrm{S}]}$ & \\
\hline \multirow[t]{2}{*}{$\overline{V_{2}}=0$} & more general & \multirow{2}{*}{$\frac{-V_{\mathrm{l}}[\mathrm{S}]}{K_{\mathrm{s} 1}+[\mathrm{S}]}$} & $\frac{V_{1} K_{\mathrm{x} 2}}{K_{2}+[\mathrm{X}]}$ \\
\hline & $\begin{array}{c}K_{\mathrm{x} 2}=\infty \text { and } \\
K_{\mathrm{s} 2}=\infty\end{array}$ & & $V_{1}$ \\
\hline \multirow[t]{3}{*}{$V_{1}=0$} & $\begin{array}{c}K_{\mathrm{x} 1}=\infty \text { and } \\
K_{\mathrm{s} 2}=0\end{array}$ & $V_{2}$ & \multirow[t]{2}{*}{$\frac{V_{2}[\mathrm{X}]}{K_{\mathrm{x} 2}+[\mathrm{X}]}$} \\
\hline & more general & \multirow[t]{2}{*}{$\frac{V_{2}[\mathrm{~S}]}{K_{\mathrm{s} 2}+[\mathrm{S}]}$} & \\
\hline & $\begin{array}{c}K_{\mathrm{s} 1}=\infty \text { and } \\
K_{\mathrm{x} 2}=0\end{array}$ & & $V_{2}$ \\
\hline
\end{tabular}

$\mathrm{V}_{\mu}$ is the difference between the reaction rate in the presence of saturating [X] and in absence of $\mathrm{X}$, both at a determined [S]; $V_{\max }$ is the value of the initial reaction rate at saturating [S] and at a determined [X]. Under the column "Class", three main groups of cases are separated: (i) partial inhibition and non-essential activation $\left(V_{1} \neq 0\right.$ and $V_{2} \neq 0$ ), (ii) total inhibition $\left(V_{2}=0\right)$; and (iii) essential activation $\left(V_{1}=0\right)$. For simplification, the classes total inhibition and essential activation were named $V_{2}=0$ and $V_{1}=0$, respectively. However, as commented in the legend to Fig. 2 , in the cases of competitive total inhibition $\left(K_{\mathrm{x} 2}=\infty\right)$ and essential activation when $\mathrm{X}$ binds first to the enzyme $\left(K_{\mathrm{s} 1}=\infty\right)$, it is better to state that, respectively, $V_{2}$ and $V_{1}$ do not exist. Obviously, in the class partial inhibition and non-essential activation, here named $V_{1} \neq 0$ and $V_{2} \neq 0$, the values of $K_{\mathrm{s} 1}$ and $K_{\mathrm{x} 2}$ must be finite and positive.

$V_{\mu}=\frac{\left(V_{2}-V_{1}\right)[\mathrm{S}]^{2}-\left(V_{1} K_{s 2}-V_{2} K_{s 1}\right)[\mathrm{S}]}{[\mathrm{S}]^{2}+\left(K_{s 1}+K_{s 2}\right)[\mathrm{S}]+K_{s 1} K_{s 2}}$

Considering [S] $>0$, i.e. a real system, the denominator of eqn. (4a) is always a positive value; so the sign of $V_{\mu}$ is the same as the sign of the numerator. $V_{\mu}$ is positive, and so $\mathrm{X}$ acts as an activator when
$\left(V_{2}-V_{1}\right)[\mathrm{S}]>V_{1} K_{\mathrm{s} 2}-V_{2} K_{\mathrm{s} 1}$

$V_{\mu}$ is negative, i.e. $\mathrm{X}$ acts as an inhibitor, when

$\left(V_{2}-V_{1}\right)[\mathrm{S}]<V_{1} K_{\mathrm{s} 2}-V_{2} K_{\mathrm{s} 1}$

Interestingly, in some cases, $V_{\mu}$ can be zero at a particular [S] different from zero. At this 
Table 2. Formulas for $K_{\mathrm{e}}, K_{\mathrm{m}}$ and $-1 / K_{\mathrm{m}}$ in particular cases of the rapid equilibrium model

\begin{tabular}{|c|c|c|c|}
\hline Conditions & $K_{\mathrm{e}}$ & $K_{\mathbf{m}}$ & $-1 / K_{m}$ \\
\hline more general & $K_{\mathrm{x} 1}+\frac{\left(K_{\mathrm{x} 2}-K_{\mathrm{x} 1}\right)[\mathrm{S}]}{K_{\mathrm{s} 2}+[\mathrm{S}]}$ & $K_{\mathrm{s} 1}+\frac{\left(K_{\mathrm{s} 2}-K_{\mathrm{s} 1}\right)[\mathrm{X}]}{K_{\mathrm{x} 2}+[\mathrm{X}]}$ & $-\frac{1}{K_{\mathrm{s} 1}}+\frac{\frac{K_{\mathrm{s} 2}-K_{\mathrm{s} 1}}{K_{\mathrm{s} 2} K_{\mathrm{s} 1}}[\mathrm{X}]}{K_{\mathrm{x} 1}+[\mathrm{X}]}$ \\
\hline $\begin{array}{c}K_{\mathrm{x} 1}=\infty \text { and } \\
K_{\mathrm{s} 2}=0\end{array}$ & $\frac{K_{\mathrm{x} 2} K_{\mathrm{s} 1}+K_{\mathrm{x} 2}[\mathrm{~S}]}{[\mathrm{S}]}$ & $\frac{K_{\mathrm{s} 1} K_{\mathrm{x} 2}}{K_{\mathrm{x} 2}+[\mathrm{X}]}$ & $-\frac{1}{K_{\mathrm{s} 1}}-\frac{[\mathrm{X}]}{K_{\mathrm{s} 1} K_{\mathrm{x} 2}}$ \\
\hline $\begin{array}{c}K_{\mathrm{x} 2}=\infty \text { and } \\
K_{\mathrm{s} 2}=\infty\end{array}$ & $K_{\mathrm{x} 1}+\frac{K_{\mathrm{x1}}}{K_{\mathrm{s} 1}}[\mathrm{~S}]$ & $K_{\mathrm{sl}}+\frac{K_{\mathrm{s} 1}}{K_{\mathrm{x} 1}}[\mathrm{X}]$ & $\frac{-\frac{K_{\mathrm{x} 1}}{K_{\mathrm{s} 1}}}{K_{\mathrm{x} 1}+[\mathrm{X}]}$ \\
\hline $\begin{array}{c}K_{\mathrm{s} 1}=\infty \text { and } \\
K_{\mathrm{x} 2}=0\end{array}$ & $\frac{K_{\mathrm{x} 1} K_{\mathrm{s} 2}}{K_{\mathrm{s} 2}+[\mathrm{S}]}$ & $\frac{K_{\mathrm{s} 2} K_{\mathrm{x} 1}+K_{\mathrm{s} 2}[\mathrm{X}]}{[\mathrm{X}]}$ & $\frac{-\frac{1}{K_{\mathrm{s} 2}}[\mathrm{X}]}{K_{\mathrm{x} 1}+[\mathrm{X}]}$ \\
\hline $\begin{array}{l}K_{\mathrm{s} 1}=K_{\mathrm{s} 2}=K_{\mathrm{s}} \\
K_{\mathrm{x} 1}=K_{\mathrm{x} 2}=K_{\mathrm{x}}\end{array}$ & $K_{\mathrm{x}}$ & $K_{\mathrm{s}}$ & $-\frac{1}{K_{s}}$ \\
\hline
\end{tabular}

The similitude between the formulas for $K_{\mathrm{e}}$ and $K_{\mathrm{m}}$ is obvious. It is interesting to note that, as schemes $A$ and $C$ in Fig. 2 have an axial symmetry considering an oblique axis, the aspect of the formulas for $K_{\mathrm{e}}$ and $K_{\mathrm{m}}$ relative to the corresponding conditions has the same axial symmetry. In Figs. 5A and 5B the possible aspects for the plots $K_{\mathrm{m}}$ versus [X] and $K_{\mathrm{e}}$ versus [S] are presented; it is not surprising that they are identical. $-1 / K_{\mathrm{m}}$ is the value of the abscissa of the intercept of the Lineweaver-Burk straight line with the horizontal axis (for short, horizontal intercept). As the values of the horizontal intercept are never positive, the plots horizontal intercept versus $[\mathrm{X}]$ are below the horizontal axis. They are, in general, rectangular hyperbolas intercepting the vertical axis at $-1 / K_{\mathrm{s} 1}$; the equation for the horizontal asymptote is $\mathrm{y}=-1 / K_{\mathrm{s} 2}$ and that for the vertical asymptote $\mathrm{x}=-K_{\mathrm{x} 1}$. These rectangular hyperbolas can be ascendant $\left(K_{\mathrm{s} 2}>K_{\mathrm{s} 1}\right)$ or descending $\left(K_{\mathrm{s} 1}>K_{\mathrm{s} 2}\right)$. When $K_{\mathrm{s} 2}=\infty$ (competitive total inhibition; case $B$, Fig. 2 ) the hyperbolas are ascendant and the horizontal asymptote is the horizontal axis itself. When $K_{\mathrm{s} 1}=\infty$ (essential activation in which X binds first; case $C$, Fig. 2) the hyperbolas are descending and intercept the origin of the axes. When $K_{\mathrm{s} 2}=0$ (case $A$, Fig. 2 ), the plots are negative slope straight lines intercepting the vertical axis at $\mathrm{y}=-1 / K_{\mathrm{s} 1}$. When $K_{\mathrm{s} 1}=K_{\mathrm{s} 2}$, the plots are horizontal straight lines given by equation $\mathrm{y}=-1 / K_{\mathrm{s}}$.

[S], X has no effect on the reaction rate. This [S] is here named $S_{\mathrm{u}}$ (from reaction rate unaffected by the modifier at that particular [S]) and can be deduced from eqn. (4). Obviously, when [S] $=0$ both $V_{\mu}$ and $v$ equal zero (see eqns. 2-4) but $S_{\mathrm{u}}$, by definition, can not be zero.

$S_{u}=\frac{V_{1} K_{s 2}-V_{2} K_{s 1}}{V_{2}-V_{1}}$

Equation (8) is the most general one to give the value of $S_{\mathrm{u}}$. In this paper $S_{\mathrm{u}}$ is considered in a wider meaning so that it can take negative values and infinity: $S_{\mathrm{u}}$ is a value different from zero that, given to [S], makes $v$ unaf- fected by changes in the value of [X]. In Table 3 , formulas for $S_{\mathrm{u}}$ and $v_{\mathrm{su}}$ (the value of $v$ when [S] $=S_{\mathrm{u}}$ ) in particular cases are presented.

The following situations can be considered regarding the values of $S_{\mathrm{u}}$ and $V_{\mu}$.

(1) $\mathrm{S}_{\mathrm{u}}$ has a finite positive value. In these cases, $\mathrm{X}$ acts as an inhibitor or an activator, depending on the value of [S], and $S_{\mathrm{u}}$ represents a sort of border or transition point between the concentration of $\mathrm{S}$ at which $\mathrm{X}$ is an activator and that at which it is an inhibitor. From eqn. (8), $S_{\mathrm{u}}$ has a finite positive value when both $K_{\mathrm{s} 1}$ and $K_{\mathrm{s} 2}$ have finite values and, simultaneously, $\left(V_{1} K_{\mathrm{s} 2}-V_{2} K_{\mathrm{s} 1}\right)$ and $\left(V_{2}-V_{1}\right)$ are both positive or both negative.

(1a) If $V_{2}>V_{1}$ and $V_{1} K_{\mathrm{s} 2}>V_{2} K_{\mathrm{s} 1}$, when [S] $>$ $\mathrm{S}_{\mathrm{u}}$, inequality (6) is true, $V_{\mu}$ is positive and $\mathrm{X}$ 
acts as an activator. When [S] $<\mathrm{S}_{\mathrm{u}}$ inequality (7) becomes true, $V_{\mu}$ is negative and $\mathrm{X}$ acts as an inhibitor.

(1b) If $V_{1}>V_{2}$ and $V_{2} K_{\mathrm{s} 1}>V_{1} K_{\mathrm{s} 2}$, when [S] $>S_{\mathrm{u}}$, the value of $\left(V_{2}-V_{1}\right)$ [S] is smaller ("more negative") than $\left(V_{1} K_{\mathrm{s} 2}-V_{2} K_{\mathrm{s} 1}\right)$; at these values of [S], inequality (7) is true, $V_{\mu}$ is negative and $\mathrm{X}$ acts as an inhibitor. When [S] $<S_{\mathrm{u}}$, the value of $\left(V_{2}-V_{1}\right)$ [S] is higher ("less negative") than $\left(V_{1} K_{\mathrm{s} 2}-V_{2} K_{\mathrm{s} 1}\right)$, inequality (6) is true, $V_{\mu}$ is positive and $\mathrm{X}$ acts as an activator. This situation includes the case $K_{\mathrm{s} 2}=0$ and $V_{1}>V_{2}$ discussed in Fig. 2 (case A3c).

According to the definition of $S_{\mathrm{u}}$, when [S] $=S_{\mathrm{u}}$, X has no effect on the reaction rate.

(2) $\mathrm{S}_{\mathrm{u}}$ has an infinite value $\left(S_{\mathrm{u}}=\infty\right)$. This situation arises when $V_{1}=V_{2}$ or $K_{\mathrm{s} 2}=\infty$ or $K_{\mathrm{s} 1}=\infty$ (eqn. 8 and Table 3). In these cases, $\mathrm{X}$ has no effect on the reaction rate when $[\mathrm{S}]=\infty$, i.e. at saturating concentrations of S. In relation to this, it should be pointed out that, although mathematically [S] is saturating when $[\mathrm{S}]=\infty$, as it will be commented later in this paper, $\mathrm{S}$ can be considered saturating when [S] > $K_{\mathrm{m}}$. As the value of $K_{\mathrm{m}}$ can vary between $K_{\mathrm{s} 1}$ (when $[\mathrm{X}]=0$ ) and $K_{\mathrm{s} 2}$ (when $[\mathrm{X}]=\infty$ ), a fixed concentration of $\mathrm{S}$ is saturating at any concentration of $\mathrm{X}$ only if, simultaneously, [S] > $\mathrm{K}_{\mathrm{s} 1}$ and $[\mathrm{S}]>>\mathrm{K}_{\mathrm{s} 2}$.

(2a) When $V_{1}=V_{2}$ (assuming that both $K_{\mathrm{s} 1}$ and $K_{\mathrm{s} 2}$ are finite values), at non-saturating [S], $\mathrm{X}$ acts as an activator when $K_{\mathrm{s} 1}>\mathrm{K}_{\mathrm{s} 2}$ (i.e. $0>$ any negative quantity; inequality 6 ), and acts as an inhibitor when $K_{\mathrm{s} 2}>\mathrm{K}_{\mathrm{s} 1}$ (i.e. $0<$ any positive quantity; inequality 7). However, as [S] increases (i.e. [S] $\rightarrow \infty$ ), $V_{\mu}$ tends to zero (see Table 1) and, at saturating concentrations of $\mathrm{S}, \mathrm{X}$ will have no effect on the reaction rate (eqn. 2). In this case, and opposite to the next two cases, as both $K_{\mathrm{s} 1}$ and $K_{\mathrm{s} 2}$ have finite values, it would be possible to find a value of [S] simultaneously much higher than both $K_{\mathrm{s} 1}$ and $K_{\mathrm{s} 2}$, and, thus, saturating at all concentrations of X.

(2b) When $K_{\mathrm{s} 2}=\infty$ (and so $K_{\mathrm{x} 2}=\infty$; case $B$, Fig. 2), $V_{\mu}$ is negative and $\mathrm{X}$ acts as an inhibi- tor. As [S] increases, $K \mathrm{e} \rightarrow \infty$ (Table 2) and, at saturating [S], $\mathrm{X}$ has no effect on the reaction rate (eqn. 2). However, as [X] tends to infinity, $K_{\mathrm{m}}$ tends to infinity $\left(K_{\mathrm{s} 2}=\infty\right)$ and so at very high [X] it would not be possible to reach saturating [S]. Indeed, in this case, $\mathrm{S}$ and $\mathrm{X}$ can not bind simultaneously to the same molecule of enzyme (Fig. 2) and so it is not possible to reach saturating concentrations of $\mathrm{S}$ if $\mathrm{X}$ is supposed to bind to the enzyme: there is no fixed concentration of $\mathrm{S}$ that could be considered saturating at all concentrations of $\mathrm{X}$. Actually, this is the case of competitive total inhibition.

(2c) When $K_{\mathrm{s} 1}=\infty$ (and so $K_{\mathrm{x} 2}=0$; case $C$, Fig. 2), $V_{\mu}$ is positive and $\mathrm{X}$ acts as an activator. As [S] increases, $K_{\mathrm{e}} \rightarrow 0$ (Table 2) and, at saturating [S], $\mathrm{X}$ has no effect on the reaction rate (eqn. 2). However, as [X] tends to zero, $K_{\mathrm{m}}$ tends to infinity $\left(\mathrm{K}_{\mathrm{s} 1}=\infty\right)$ and so at very low [X] it would not be possible to reach saturating [S]. Indeed, in this case $\mathrm{S}$ cannot bind to a molecule of enzyme if $\mathrm{X}$ has not bound previously (Fig. 2), and so if $[\mathrm{X}]=0$, [S] can never be saturating. Once again, there is no fixed concentration of $\mathrm{S}$ that could be considered saturating at all concentrations of $\mathrm{X}$.

(3) $\mathrm{S}_{\mathrm{u}}$ has a finite negative value. In this case $S_{\mathrm{u}}$ has no chemical meaning but it has a kinetic meaning: the type of effect of $\mathrm{X}$ is independent of the concentration of S. $S_{\mathrm{u}}$ has a finite negative value when, simultaneously, $V_{2}$ $>V_{1}, V_{2} K_{s 1}>V_{1} K_{\mathrm{s} 2}$ and $K_{\mathrm{s} 1} \neq \infty$ or when, simultaneously, $V_{1}>V_{2}, V_{1} K_{\mathrm{s} 2}>V_{2} K_{\mathrm{s} 1}$ and $K_{\mathrm{s} 2}$ $\neq \infty$. When $V_{2}>V_{1}, \mathrm{X}$ is an activator at any concentration of $\mathrm{S}$ (any positive quantity $>$ any negative quantity; inequality 6 ). When $V_{1}$ $>V_{2}, \mathrm{X}$ is an inhibitor at any concentration of $\mathrm{S}$ (any negative quantity < any positive quantity; inequality 7).

(4) $\mathrm{S}_{\mathrm{u}}$ does not exist; i.e. the only value of [S] at which $X$ has no effect is zero. As stated above when $[\mathrm{S}]=0, \mathrm{X}$ is never a modifier: $v=0$ in every case at any [X]. $S_{\mathrm{u}}$ does not exist when $V_{1}$ $\neq \mathrm{V}_{2}$ and $V_{1} K_{\mathrm{s} 2}=V_{2} K_{\mathrm{s} 1}$, assuming both $K_{\mathrm{s} 1}$ and $K_{\mathrm{s} 2} \neq \infty$ (see eqn. 8 and Table 3 ). The type of effect of $\mathrm{X}$ is independent of [S] and can be 
Table 3. Formulas for $S_{\mathrm{u}}$ and $v_{\mathrm{su}}$ in particular c

\begin{tabular}{|c|c|c|c|}
\hline Class & Subclass & $S_{\mathrm{u}}$ & $v_{S \mathrm{u}}$ \\
\hline \multirow[t]{5}{*}{$\begin{array}{l}V_{1 \neq 0} \\
\text { and } \\
V_{2 \neq 0}\end{array}$} & more general & $\frac{V_{1} K_{\mathrm{s} 2}-V_{2} K_{\mathrm{s} 1}}{V_{2}-V_{1}}$ & $\frac{V_{1} K_{\mathrm{s} 2}-V_{2} K_{\mathrm{s} 1}}{K_{\mathrm{s} 2}-K_{\mathrm{s} 1}}$ \\
\hline & $\begin{array}{c}K_{\mathrm{x} 1}=\infty \text { and } \\
K_{\mathrm{s} 2}=0\end{array}$ & $\frac{V_{2} K_{\mathrm{s} 1}}{V_{1}-V_{2}}$ & $V_{2}$ \\
\hline & $\begin{array}{l}K_{\mathrm{s} 1}=K_{\mathrm{s} 2}=K_{\mathrm{s}} \\
K_{\mathrm{x} 1}=K_{\mathrm{x} 2}=K_{\mathrm{x}}\end{array}$ & $-K_{\mathrm{s}}$ & $\infty$ \\
\hline & $\begin{aligned} V_{1} K_{\mathrm{s} 2} & =V_{2} K_{\mathrm{s} 2} \\
V_{1} K_{\mathrm{x} 2} & =V_{2} K_{\mathrm{x} 1}\end{aligned}$ & does not exist & does not exist \\
\hline & $V_{1}=V_{2}=V$ & $\infty$ & $\bar{V}$ \\
\hline \multirow[t]{4}{*}{$V_{2}=0$} & more general & $-K_{\mathrm{s} 2}$ & $\frac{V_{1} K_{\mathrm{s} 2}}{K_{\mathrm{s} 1}-K_{\mathrm{s} 2}}$ \\
\hline & $\begin{array}{c}K_{\mathrm{x} 2}=\infty \text { and } \\
K_{\mathrm{s} 2}=\infty\end{array}$ & $\infty$ & $V_{1}$ \\
\hline & $\begin{array}{c}K_{\mathrm{x} 1}=\infty \text { and } \\
K_{\mathrm{s} 2}=0\end{array}$ & does not exist & does not exist \\
\hline & $\begin{array}{l}K_{\mathrm{s} 1}=K_{\mathrm{s} 2}=K_{\mathrm{s}} \\
K_{\mathrm{x} 1}=K_{\mathrm{x} 2}=K_{\mathrm{x}}\end{array}$ & $-K_{\mathrm{s}}$ & $\infty$ \\
\hline \multirow[t]{4}{*}{$V_{1}=0$} & more general & \multirow[t]{2}{*}{$-K_{\mathrm{sl}}$} & $\frac{V_{2} K_{\mathrm{s} 1}}{K_{\mathrm{s} 1}-K_{\mathrm{s} 2}}$ \\
\hline & $\begin{array}{c}K_{\mathrm{x} 1}=\infty \text { and } \\
K_{\mathrm{s} 2}=0\end{array}$ & & \multirow[t]{2}{*}{$V_{2}$} \\
\hline & $\begin{array}{c}K_{\mathrm{s} 1}=\infty \text { and } \\
K_{\mathrm{x} 2}=0\end{array}$ & $\infty$ & \\
\hline & $\begin{array}{l}K_{\mathrm{s} 1}=K_{\mathrm{s} 2}=K_{\mathrm{s}} \\
K_{\mathrm{x} 1}=K_{\mathrm{x} 2}=K_{\mathrm{x}}\end{array}$ & $-K_{\mathrm{s}}$ & $\infty$ \\
\hline
\end{tabular}

$S_{\mathrm{u}}$ is a value different from zero that, given to [S], makes $v$ unaffected by changes in the value of [X]; $v_{\mathrm{su}}$ is the value of $v$ for [S] = $S_{\mathrm{u}} . S_{\mathrm{u}}$ may also be defined as the value of [S] where the Lineweaver-Burk straight lines relative to different values of [X] cross. Classes are defined in Table 1. The restrictions in the domain of the function $v=f([\mathrm{~S}])$ considering eqn. (2) ([S] $\neq-K_{\mathrm{s} 1}$ and $[\mathrm{S}] \neq$ $-K_{\mathrm{s} 2}$ ) or eqn. (9) ([S] $\neq-K_{\mathrm{m}}$ ) can be overcome if they are rewritten in the Lineweaver-Burk way (eqn. 12), because here the only restriction to the domain is that [S] must be different from zero, what is already imposed by the definition of $S_{\mathrm{u}}$. In order to calculate $S_{\mathrm{u}}$ one could calculate $\frac{\delta \frac{1}{v}}{\delta[\mathrm{X}]}$ and then the values of $1 /[\mathrm{S}]$ that makes $\frac{\delta 1_{v}}{\delta[\mathrm{X}]}=0$. When $S_{\mathrm{u}}$ does not exist this means that the Lineweaver-Burk straight lines relative to different values of [X] are parallel. Since in these plots the horizontal axis represents $1 /[\mathrm{S}]$, when $S_{\mathrm{u}}=\infty$ the straight lines cross on the vertical axis, and when $S_{\mathrm{u}}=-K_{\mathrm{s}}$ they cross on the horizontal axis.

deduced from inequalities (6) and (7): when $V_{2}>V_{1}, \mathrm{X}$ is an activator (i.e. any positive quantity $>0$ ); when $V_{1}>V_{2}, \mathrm{X}$ is an inhibitor (i.e. any negative quantity $<0$ ). This situation includes the case $V_{2}=0$ and $K_{\mathrm{s} 2}=0$ (uncompetitive total inhibition; case A1, Fig. 2). In this case, $V_{\mu}$ is negative (Table 1 ) and so inhibition occurs at all concentrations of $\mathrm{S}$.
(5) $\mathrm{S}_{\mathrm{u}}$ has an indeterminate value. In the particular case in which $V_{1}=V_{2}$ and $K_{\mathrm{s} 1}=\mathrm{K}_{\mathrm{s} 2}$ the value of $S_{\mathrm{u}}$ can not be calculated and neither inequality (6) nor (7) applies: $\mathrm{X}$ is never (at any [S]) a modifier of the reaction rate.

In Table 4 the conditions in which $\mathrm{X}$ is activator, inhibitor, or has no effect on the reaction rate are summarized (see also ref. [5], p. 115). 
Table 4. Relationship between $V_{1}, V_{2}$, equilibrium constants, the concentration of $S$, and the effect of a modifier $\mathrm{X}$ on the reaction rate

\begin{tabular}{|c|c|c|c|}
\hline & $V_{1} K_{\mathrm{s} 2}>V_{2} K_{\mathrm{s} 1}$ & $V_{1} K_{\mathrm{s} 2}=V_{2} K_{\mathrm{s} 1}$ & $V_{2} K_{\mathrm{s} 1}>V_{1} K_{\mathrm{s} 2}$ \\
\hline$V_{2}>V_{1}$ & $\begin{array}{l}{[\mathrm{S}]<S_{\mathrm{u}}: \text { Inhibitor }} \\
{[\mathrm{S}]=S_{\mathrm{u}}: \text { No effect }} \\
{[\mathrm{S}]>S_{\mathrm{u}}: \text { Activator }}\end{array}$ & $\begin{array}{c}\text { Activator } \\
\left(S_{\mathrm{u}} \text { does not exist }\right)\end{array}$ & $\begin{array}{l}\text { Activator }(1) \\
\quad\left(S_{\mathrm{u}}<0\right)\end{array}$ \\
\hline$V_{1}=V_{2}$ & $\begin{array}{c}\text { Inhibitor( }(2) \\
\left(K_{\mathrm{s} 2}>K_{\mathrm{s} 1} ; S_{\mathrm{u}}=\infty\right)\end{array}$ & $\mathrm{X}$ is not a modifier & $\begin{array}{c}\text { Activator(2) } \\
\left(K_{\mathrm{s} 1}>K_{\mathrm{s} 2} ; S_{\mathrm{u}}=\infty\right)\end{array}$ \\
\hline$V_{1}>V_{2}$ & $\begin{array}{l}\text { Inhibitor(3) } \\
\quad\left(S_{\mathrm{u}}<0\right)\end{array}$ & $\begin{array}{c}\text { Inhibitor }(4) \\
\left(S_{\mathrm{u}} \text { does not exist }\right)\end{array}$ & $\begin{array}{l}{[\mathrm{S}]<S_{\mathrm{u}}: \text { Activator }} \\
{[\mathrm{S}]=S_{\mathrm{u}}: \text { No effect }} \\
{[\mathrm{S}]>S_{\mathrm{u}}: \text { Inhibitor }}\end{array}$ \\
\hline
\end{tabular}

Only the cases in which all the equilibrium constants have nonzero and finite values are presented; the effects shown are those observed at non-saturating concentrations of S. ${ }^{(1)}$ Includes all the cases in which X is an essential activator $\left(V_{1}=0\right.$ or $\left.K_{\mathrm{s} 1}=\infty\right)$. If $K_{\mathrm{s} 1}=\infty$ (essential activation in which X binds first; case $C$, Fig. 2), $S_{\mathrm{u}}=\infty$ and X has no effect at saturating concentrations of S; however, when $[\mathrm{X}] \rightarrow 0,[\mathrm{~S}]$ can not be saturating, because the value of $K_{\mathrm{m}}$ tends to infinity $\left(K_{\mathrm{m}} \rightarrow \mathrm{K}_{\mathrm{s} 1}=\infty\right)$. ${ }^{(2)}$ At saturating concentrations of $\mathrm{S}\left([\mathrm{S}] \gg K_{\mathrm{s} 1}\right.$ and $[\mathrm{S}] \gg K_{\mathrm{s} 2}$ ), X has no effect on the reaction rate even at saturating concentrations. ${ }^{(3)}$ Includes the cases when $\mathrm{X}$ is a total inhibitor $\left(V_{2}=0\right.$ or $\left.K_{\mathrm{s} 2}=\infty\right)$, except the uncompetitive total inhibition $\left(V_{2}=0\right.$ and $\left.K_{\mathrm{s} 2}=0\right)$. If $K_{\mathrm{s} 2}=\infty$ (competitive total inhibition; case $B$, Fig. 2), $S_{\mathrm{u}}=\infty$ and X has no effect at saturating concentrations of S; however, when [X] $\rightarrow \infty$, [S] can not be saturating, because the value of $K_{\mathrm{m}}$ tends to infinity $\left(K_{\mathrm{m}} \rightarrow K_{\mathrm{s} 2}=\infty\right)$. ${ }^{(4)}$ Includes the case when $V_{2}=0$ and $K_{\mathrm{s} 2}=0$ (uncompetitive total inhibition; case A1, Fig. 2).

$V_{\text {max }}, K_{\mathrm{m}}$ AND LINEWEAVER-BURK

\section{PLOTS}

The classic equation relating $v$ with $V_{\max }$, $K_{\mathrm{m}}$ and [S] is

$v=\frac{V_{\max }[\mathrm{S}]}{K_{m}+[\mathrm{S}]}$

where in our case,

$V_{\max }=\frac{V_{1} K_{x 2}+V_{2}[\mathrm{X}]}{K_{x 2}+[\mathrm{X}]}$

or (see ref. [17])

$V_{\max }=V_{1}+\frac{\left(V_{2}-V_{1}\right)[\mathrm{X}]}{K_{x 2}+[\mathrm{X}]}$

and

$$
K_{m}=\frac{K_{s 1} K_{x 2}+K_{s 2}[\mathrm{X}]}{K_{x 2}+[\mathrm{X}]}
$$

or (see ref. [17])

$K_{m}=K_{s 1}+\frac{\left(K_{s 2}-K_{s 1}\right)[\mathrm{X}]}{K_{x 2}+[\mathrm{X}]}$

Equation (9) shows the effect of varying [S] on the reaction rate at a fixed [X]; the values of $V_{\max }$ and $K_{\mathrm{m}}$ in the presence of a fixed [X] can be calculated using, respectively, eqns. (10) and (11) (or 10a and 11a).

The similitude between eqns. (10) and (11), and also between eqns. (10a) and (11a), requires some comments:

(a) Equation (10) shows that the value of $V_{\max }$ is a sort of pondered mean of $V_{1}$ and $V_{2}$, $K_{\mathrm{x} 2}$ and [X] being the pondering factors to be applied to $V_{1}$ and $V_{2}$, respectively. Similarly, eqn. (11) shows that the value of $K_{\mathrm{m}}$ is a sort 


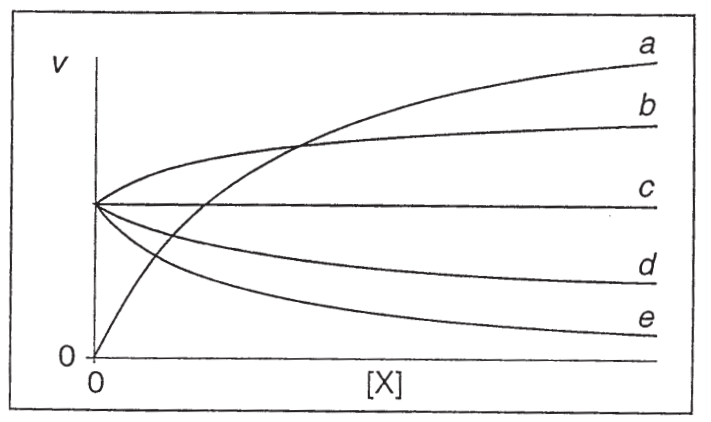

Figure 3. Plots of the initial velocity $v$ versus concentration of modifier [X] at a determined concentration of a substrate.

Depending on the values of the parameters in eqn. (2) (which depend on the concentration of substrate) the following situations can be obtained: $(a)$ an increasing rectangular hyperbola that passes through the origin of the axes $\left(v_{\text {xо }}=0, V_{\mu}>0\right)$; $\mathrm{X}$ is an essential activator; $(b)$ an increasing rectangular hyperbola that intercepts the vertical axis at a positive value $\left(v_{\mathrm{xo}} \neq 0\right.$ and $\left.V_{\mu}>0\right)$; $\mathrm{X}$ acts as a non-essential activator; $(c)$ a straight line above, and parallel to the horizontal axis $\left(V_{\mu}=0\right)$; $\mathrm{X}$ has no effect on the reaction rate at a determined concentration of substrate ([S] $\left.=S_{\mathrm{u}}\right) ;(d)$ a decreasing rectangular hyperbola intercepting the vertical axis at a positive value and with the horizontal asymptote above the horizontal axis $\left(v_{\mathrm{xo}} \neq 0,-v_{\mathrm{xo}}<V_{\mu}<0\right)$; $\mathrm{X}$ acts as a partial inhibitor; (e) a decreasing rectangular hyperbola also intercepting the vertical axis at a positive value and with the horizontal asymptote coincident with the horizontal axis $\left(v_{\mathrm{xo}} \neq 0, V_{\mu}=-v_{\mathrm{xo}}\right)$; $\mathrm{X}$ is a total inhibitor. When $\mathrm{X}$ is an essential activator that binds first to the enzyme (case $C$, Fig. 2) as $\mathrm{X}$ tends to zero the reaction rate tends to zero, but at saturating [S], since the value of $K_{\mathrm{e}}$ is very low $\left(K_{\mathrm{x} 2}=0\right)$, the saturating concentrations of X can be attained at very low [X]. So at very high [S] a pattern between $a$ and $c$ is produced. When $\mathrm{X}$ is a competitive total inhibitor (case $B$, Fig. 2) as $\mathrm{X}$ tends to infinity the reaction rate tends to zero, but at saturating [S], since the value of $K_{\mathrm{e}}$ is very high $\left(K_{\mathrm{x} 2}=\right.$ $\infty$ ), X has no effect on $v$. So, at very high [S], saturating for the concentrations of $\mathrm{X}$ plotted, pattern $c$ is produced; although, if the concentrations of X plotted are high enough to dissociate $\mathrm{S}$ from the enzyme, [S] is no longer saturating and, in consequence, pattern $e$ is produced.

of pondered mean of $K_{\mathrm{s} 1}$ and $K_{\mathrm{s} 2}, K_{\mathrm{x} 2}$ and [X] being also the pondering factors to be applied to $K_{\mathrm{s} 1}$ and $K_{\mathrm{s} 2}$, respectively.

(b) Both the plots $V_{\max }$ versus [X] and $K_{\mathrm{m}}$ versus $[\mathrm{X}]$ are, in general, rectangular hyperbolas

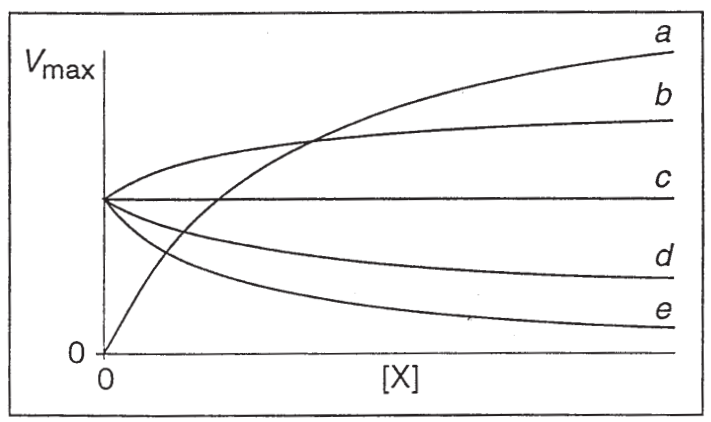

Figure 4. The plot $V_{\max }$ versus $[\mathrm{X}]$ can show one of five different aspects.

These aspects are the same as those for $v$ versus [X] shown in Fig. 3: ( $a$ ) an increasing rectangular hyperbola that passes through the origin of the axes $\left(V_{1}=0\right)$; $\mathrm{X}$ is as an essential activator; (b) an increasing rectangular hyperbola that intercepts the vertical axis at a positive value (both $V_{1}$ and $V_{2} \neq 0, V_{2}>V_{1}$ ); generally, $\mathrm{X}$ is a non-essential activator, but if $S_{\mathrm{u}}$ is finite and positive, it does not act as a modifier at [S] $=S_{\mathrm{u}}$ and acts as a partial inhibitor at [S] $<S_{\mathrm{u}} ;(c)$ a straight line above and parallel to the horizontal axis $\left(V_{1}=V_{2}\right.$ or $K_{\mathrm{s} 1}=\infty$ or $\left.K_{\mathrm{x} 2}=\infty\right)$; at saturating [S], $\mathrm{X}$ has no effect on the reaction rate; at non-saturating [S], $\mathrm{X}$ acts as an essential activator that binds first to the enzyme $\left(K_{\mathrm{s} 1}=\infty\right.$ and $\left.K_{\mathrm{x} 2}=0\right)$, as a competitive total inhibitor $\left(K_{\mathrm{x} 2}=\infty\right.$ and $\left.K_{\mathrm{s} 2}=\infty\right)$, as a competitive partial inhibitor $\left(V_{1}=V_{2}\right.$ and $K_{\mathrm{s} 2}>K_{\mathrm{s} 1}$, assuming $\left.K_{\mathrm{s} 2} \neq \infty\right)$ or as a non-essential activator $\left(V_{1}=V_{2}\right.$ and $K_{\mathrm{s} 1}>K_{\mathrm{s} 2}$, assuming $\left.K_{\mathrm{s} 1} \neq \infty\right)$; $(d)$ a decreasing rectangular hyperbola intercepting the vertical axis at a positive value and with the horizontal asymptote above the horizontal axis (both $V_{1}$ and $V_{2} \neq 0, V_{1}>V_{2}$ ); generally, $\mathrm{X}$ is an inhibitor, but if $S_{\mathrm{u}}$ is finite and positive it does not act as a modifier at [S] $=S_{\mathrm{u}}$ and acts as a non-essential activator at [S] $<S_{\mathrm{u}}$; $(e)$ a decreasing rectangular hyperbola also intercepting the vertical axis at a positive value and with the horizontal asymptote coincident with the horizontal axis $\left(V_{2}=0\right)$; $\mathrm{X}$ is a total inhibitor of any type except the competitive type. In all the cases, except case $c, K_{\mathrm{x} 2}$ has a nonzero finite value. If the curves in this graph were drawn from experimental data, the graph could be used to obtain the values of $V_{1}$ and $V_{2}: V_{1}$ is the value of the ordinate of the intercept with the vertical axis; $V_{2}$ is the value of the ordinate of the horizontal asymptote (except in case $c$, in which $V_{2}=$ $V_{1}$ ). The value of the abscissa of the vertical asymptote is $-K_{\mathrm{x} 2}$ (except in case $c$, in which there is no vertical asymptote).

that intercept the vertical axis at $V_{\max }=V_{1}$ or $K_{\mathrm{m}}=K_{\mathrm{s} 1}$, the equations for the horizontal asymptotes are $V_{\max }=V_{2}$ and $K_{\mathrm{m}}=K_{\mathrm{s} 2}$, respec- 
A

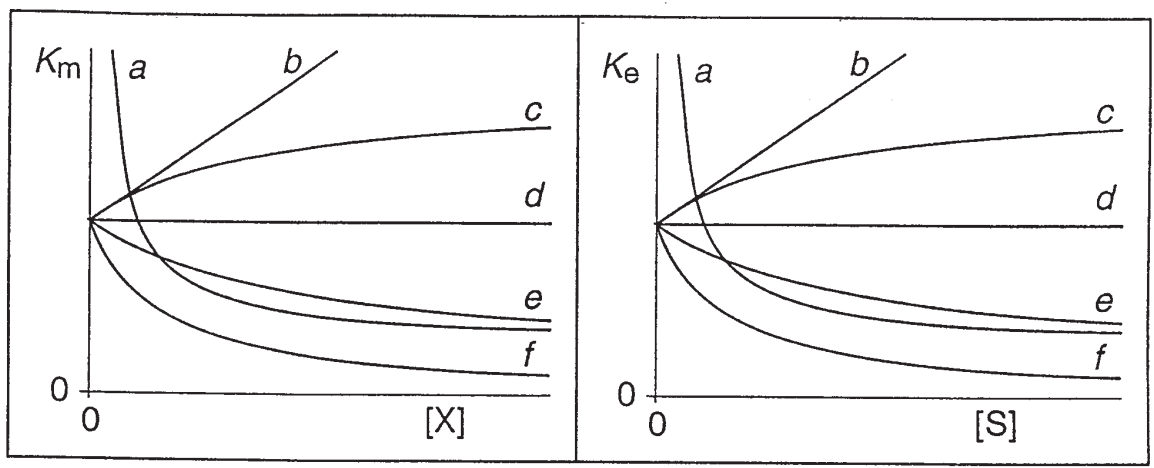

Figure 5. Plots $K_{\mathrm{m}}$ versus [X] (panel A) and $K_{\mathrm{e}}$ versus [S] (panel B) can show one of six different aspects.

These aspects are: $(a)$ a decreasing rectangular hyperbola with horizontal asymptote above the horizontal axis and the vertical one being the vertical axis itself; (b) a straight line whose values of the slope and the intercept with the vertical axis are both positive; $(c)$ an increasing rectangular hyperbola that intercepts the vertical axis at a positive value; $(d)$ a straight line above and parallel to the horizontal axis; $(e)$ a decreasing rectangular hyperbola intercepting the vertical axis at a positive value and with the horizontal asymptote above the horizontal axis; $(f)$ a decreasing rectangular hyperbola also intercepting the vertical axis at a positive value and with the horizontal asymptote coincident with that of the horizontal axis. In cases $b, c, d$ and $e$ the two graphs correspond to the same situations. In case $b\left(K_{\mathrm{x} 2}=\infty\right.$ and $K_{\mathrm{s} 2}=\infty$; case $B$, Fig. 2$) \mathrm{X}$ acts as a competitive total inhibitor. In case $d\left(K_{\mathrm{s} 1}=K_{\mathrm{s} 2}\right.$ and so $\left.K_{\mathrm{x} 1}=K_{\mathrm{x} 2}\right)$ the order in which $\mathrm{X}$ and $\mathrm{S}$ bind to the enzyme is random, $\mathrm{S}$ binds with the same affinity to $\mathrm{E}$ and EX, and $\mathrm{X}$ binds with the same affinity to $\mathrm{E}$ and ES; $\mathrm{X}$ can be an essential activator $\left(V_{1}=0\right)$, a total inhibitor of the non-competitive type $\left(V_{2}=0\right)$, a non-essential activator $\left(V_{2}>V_{1}\right)$ or a partial inhibitor $\left(V_{1}>V_{2}\right)$. In cases $c\left(K_{\mathrm{s} 2}>K_{\mathrm{s} 1}\right.$ and so $\left.K_{\mathrm{x} 2}>K_{\mathrm{x} 1}\right)$ and $e\left(K_{\mathrm{s} 1}>K_{\mathrm{s} 2}\right.$ and so $\left.K_{\mathrm{x} 1}>K_{\mathrm{x} 2}\right)$ neither equilibrium constant equals zero or infinity; the order of $\mathrm{S}$ and $\mathrm{X}$ binding to the enzyme is random, but $\mathrm{S}$ and $\mathrm{X}$ bind with different affinity to $\mathrm{E}$ and to $\mathrm{EX}$ or ES; this affinity is stronger to $\mathrm{E}$ (case $c$ ) or stronger to EX or ES (case e); depending on the values of $V_{1}, V_{2}, K_{\mathrm{s} 1}, K_{\mathrm{s} 2}$, [S] and $S_{\mathrm{u}}$, X can act as an essential or a non-essential activator, as a partial or total inhibitor or, when $S_{\mathrm{u}}$ is finite and positive, it would have no effect at $[\mathrm{S}]=S_{\mathrm{u}}$. In case $a$ of panel A and in case $f$ of panel B $\left(K_{\mathrm{s} 1}=\infty\right.$ and $K_{\mathrm{x} 2}=0$; case $C$, Fig. 2) X is an essential activator that binds first to the enzyme. In case $f$ of panel A and in case $a$ of panel B $\left(K_{\mathrm{x} 1}=\infty\right.$ and $K_{\mathrm{s} 2}=0$; case $A$, Fig. 2) $\mathrm{S}$ binds first to the enzyme, and $\mathrm{X}$ can be an uncompetitive total inhibitor $\left(V_{2}=0\right)$, an essential activator $\left(V_{1}=0\right)$, a non-essential activator at all [S] $\left(V_{2}>V_{1}\right)$, or a non-essential activator at non-saturating [S] $\left(V_{1}=V_{2}\right)$; when $V_{1}>V_{2}$ acts as an activator, an inhibitor or has no effect depending on the relationship between [S] and $S_{\mathrm{u}}$. If the curves in these graphs were drawn from experimental data, the graph could be used to obtain the values of the four equilibrium constants (cf. Fig. 1). Graph A: the ordinate of the intercept of the curves with the vertical axis is, in all cases, $K_{\mathrm{s} 1}$; in case $b, K_{\mathrm{s} 2}=\infty$ and $K_{\mathrm{x} 2}=\infty$; in case $d, K_{\mathrm{s} 2}=\mathrm{K}_{\mathrm{s} 1}$; in the other cases, the ordinate of the points of the horizontal asymptote is $K_{\mathrm{s} 2}$, and the symmetrical line of the abscissa of the points of the vertical asymptote is $K_{\mathrm{x} 2}$. Graph B: the ordinate of the intercept of the curves with the vertical axis is, in all cases, $K_{\mathrm{x} 1}$; in case $b, K_{\mathrm{s} 2}=\infty$ and $K_{\mathrm{x} 2}=\infty$; in case $d, K_{\mathrm{x} 2}=K_{\mathrm{x} 1}$; in the other cases, the ordinate of the points of the horizontal asymptote is $K_{\mathrm{x} 2}$, and the symmetrical line of the abscissa of the points of the vertical asymptote is $K_{\mathrm{s} 2}$. Note that in cases $c, e$ and $f$ only one of the graphs is required: any of them gives directly the value of three equilibrium constants, and the forth can be obtained using eqn. (1). In other cases both graphs may be needed.

tively; the equations for the vertical asymptotes are in both cases $[\mathrm{X}]=-K_{\mathrm{x} 2}$ (see eqns. 10a and 11a). The equations relating $V_{\max }$ and $K_{\mathrm{m}}$ with [X] in particular cases are shown, respectively, in Tables 1 and 2. In Figs. 4 and $5 \mathrm{~A}$ all the possible aspects of these plots are presented.
From eqns. (11) or (11a) and the definitions of each of the dissociation constants, eqn. (11b) can be deduced (see Appendix B):

$$
K_{m}=\frac{[\mathrm{S}]([\mathrm{E}]+[\mathrm{EX}])}{[\mathrm{ES}]+[\mathrm{ESX}]}
$$


This equation shows that in the presence of $\mathrm{X}$, the $K_{\mathrm{m}}$ is no more the dissociation constant for the complex $\mathrm{ES}\left(K_{\mathrm{s} 1}\right)$; it is a sort of equilibrium constant for the dissociation of $\mathrm{S}$ from the enzyme complexes containing $\mathrm{S}$ (ES + $\mathrm{ESX} \leftrightarrow \mathrm{E}+\mathrm{EX}+\mathrm{S}$ ). Note that the denominator (eqn. 11b) is the sum of the concentrations of the enzyme complexes containing $\mathrm{S}$, and the numerator is the product of [S] by the sum of the concentrations of the enzyme complexes not containing $\mathrm{S}$.

The effect of the modifier on the reaction rate can be easily visualized with the help of Lineweaver-Burk (LB) plots. The equation representing $1 / v$ versus $1 /[\mathrm{S}]$ is:

$$
\begin{aligned}
& \frac{1}{v}=\frac{K_{x 2}+[\mathrm{X}]}{V_{1} K_{x 2}+V_{2}[\mathrm{X}]}+ \\
& \frac{K_{s 1} K_{s 2}+K_{s 2}[\mathrm{X}]}{V_{1} K_{x 2}+V_{2}[\mathrm{X}]} \frac{1}{[\mathrm{~S}]}
\end{aligned}
$$

Equation (12) can be rearranged to show more clearly that the plots of vertical intercept versus $[\mathrm{X}]$ and slope versus $[\mathrm{X}]$ are, in general, rectangular hyperbolas (see ref. [17]):

$$
\begin{aligned}
& \frac{1}{v}=\left(\frac{1}{V_{1}}+\frac{\frac{V_{1}-V_{2}}{V_{1} V_{2}}[\mathrm{X}]}{\frac{V_{1} K_{x 2}}{V_{2}}+[\mathrm{X}]}\right)+ \\
& +\left(\frac{K_{s 1}}{V_{1}}+\frac{\frac{V_{1} K_{s 2}-V_{2} K_{s 1}}{V_{1} V_{2}}[\mathrm{X}]}{\frac{V_{1} K_{x 2}}{V_{2}}+[\mathrm{X}]}\right) \frac{1}{[\mathrm{~S}]}
\end{aligned}
$$

In Tables 2 and 5 , formulas for $-1 / K_{\mathrm{m}}$, $K_{\mathrm{m}} / V_{\max }$, and $1 / V_{\max }$, (respectively, the value of the abscissa on the intercept of the LB straight lines with the horizontal axis, the value of the slopes, and the value of the ordinate on the intercept with the vertical axis) in particular cases are presented. In the legends to these Tables a discussion on the possible as- pects of the plots of those parameters versus [X] can be found.

Depending on the type of enzyme modification, the LB straight lines for different concentrations of $\mathrm{X}$ may cross at a point $\mathrm{P}$ with coordinates $1 / S_{\mathrm{u}}$ and $1 / v_{\mathrm{su}}$ indicating, respectively, the inverse of the substrate concentration at which the reaction rate is unaffected by the modifier and the inverse of the reaction rate attained at that concentration of substrate. As can be deduced from eqns. (8) and (12), the value of $1 / v_{\text {su }}$ can be calculated by applying eqn. (13) (see Appendix B):

$\frac{1}{v_{s u}}+\frac{K_{s 2}-K_{s 1}}{V_{1} K_{s 2}-V_{2} K_{s 1}}$

The different spatial positions of point $\mathrm{P}$ are visualized in Figs. 6, 7 and 8.

In Fig. 6, cases when $\mathrm{X}$ is a partial inhibitor or a non-essential activator are represented. The continuous line represents $1 / v$ versus 1/[S] in absence of modifier; broken lines (activation) and dotted lines (inhibition) represent the limit to which the LB straight lines tend when $\mathrm{X}$ tends to infinity.

In Fig. 7, cases when $\mathrm{X}$ is a total inhibitor are represented $\left(V_{2}=0\right.$ or $\left.K_{\mathrm{x} 2}=\infty\right)$. Again the continuous line represents $1 / v$ versus $1 /$ [S] in absence of modifier. When $[\mathrm{X}]$ tends to infinity the slope tends to infinity (see Table 5); the vertical dotted lines are the limit to which the LB straight lines tend when [X] tends to infinity; the equation for these vertical lines is always $1 /[\mathrm{S}]=-1 / K_{\mathrm{S} 2}$.

In Fig. 8, cases when $\mathrm{X}$ is an essential activator are represented $\left(V_{1}=0\right.$ or $\left.K_{\mathrm{s} 1}=\infty\right)$. Unlike in Fig. 6 and 7, the two continuous lines (the horizontal above the horizontal axis and the oblique) represent $1 / v$ versus $1 /$ [S] when the concentration of $\mathrm{X}$ is saturating. When [X] tends to zero the slope tends to infinity (see Table 5); the vertical dotted lines are the limit to which the LB straight lines tend when [X] tends to zero; the equation for these vertical lines is always $1 /[\mathrm{S}]=-1 / K_{\mathrm{s} 1}$. In Figs. 7 and 8 
the possible positions of point $\mathrm{P}$ are the same as those in Fig. 6, except that it can not be located in the first quadrant.

(1) When point $P$ is (case $a$ in Fig. 6) in the first quadrant the situation is the same as discussed in the preceding section under (1): $S_{\mathrm{u}}$ has a finite positive value. When $V_{2}>V_{1}$, $V_{1} K_{\mathrm{s} 2}>V_{2} K_{\mathrm{s} 1}$ and so $K_{\mathrm{s} 2}>K_{\mathrm{s} 1}$, the effect of $\mathrm{X}$ is to rotate counterclockwise the LB straight line about point $\mathrm{P}$, moving the points intercepting the horizontal and the vertical axes to the origin of the axes $(0,0)$ : the values of the slope, of $V_{\max }$ and of $K_{\mathrm{m}}$ are increased by X. As $K_{\mathrm{s} 2} \neq \infty$, the point $(0,0)$ is never reached. When $V_{1}>V_{2}, V_{2} K_{\mathrm{s} 1}>V_{1} K_{\mathrm{s} 2}$ and so $K_{\mathrm{s} 1}>K_{\mathrm{s} 2}$ the effect of $\mathrm{X}$ is to rotate clockwise the LB straight line about point $\mathrm{P}$, moving the intercepting points with the horizontal and the vertical axes away from the origin of the axes: the values of the slope, of $V_{\max }$ and of $K_{\mathrm{m}}$ are decreased by X. In Fig. 9 an example of a case when $\mathrm{X}$ acts as an activator or as an inhibitor depending on the substrate concentration is presented using $v$ versus $[\mathrm{S}]$ plots.

(2) When point $P$ is on the upper half of the vertical axis (cases $b$ in Figs. 6, 7 and 8) the situation is that discussed in the preceding section under (2): $S_{\mathrm{u}}=\infty$. When $K_{\mathrm{s} 2}>K_{\mathrm{s} 1}$ the effect of $\mathrm{X}$ is to rotate counterclockwise the LB straight line about point $\mathrm{P}$, moving the intercepting point with the horizontal axis to the origin of the axes; $\mathrm{X}$ is a competitive inhibitor: it increases $K_{\mathrm{m}}$ and so the values of [S] that could be considered saturating, without affecting $V_{\max }$. When $K_{\mathrm{s} 2}=\infty$ (case $b$ in Fig. 7), $\mathrm{X}$ is a competitive total inhibitor: as [X] increases, the intercept with the horizontal axis moves up to the origin of the axes $\left(1 / K_{\mathrm{s} 2}=0\right)$. When $K_{\mathrm{s} 1}>K_{\mathrm{s} 2}$ the effect of $\mathrm{X}$ is to rotate clockwise the LB straight line about point $\mathrm{P}$, moving the intercepting point with the horizontal axis away from the origin of the axes: $\mathrm{X}$ decreases $K_{\mathrm{m}}$ and so the values of [S] that could be considered saturating, without affecting $V_{\max }$. When $K_{\mathrm{s} 1}=\infty$ (case $b$ in Fig. 8), $\mathrm{X}$ is an essential activator that binds first to the enzyme: as [X] approaches to zero, the in-

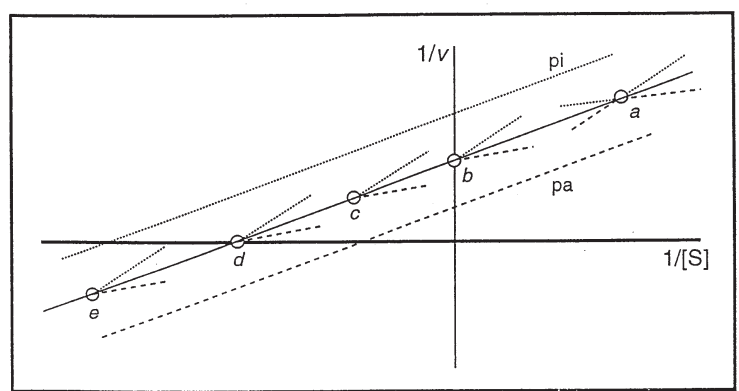

Figure 6. The crossing point $P$ in LineweaverBurk plots in the cases of partial inhibition or non-essential activation (both $V_{1}$ and $V_{2} \neq 0$ and both $K_{\mathrm{s} 1}$ and $K_{\mathrm{x} 2} \neq \infty$ ).

The LB straight lines representing $1 / v=/(1 /[\mathrm{S}])$ for $[\mathrm{X}]=0$ are always oblique and their slopes are positive; they are here represented by a continuous line. Generally, at a given set of constants, all the straight lines representing $1 / v=f(1 /[\mathrm{S}])$ at different $[\mathrm{X}]$ cross in one point $\mathrm{P}$. The $\mathrm{x}$ - and $\mathrm{y}$-coordinates of point $\mathrm{P}$ are, respectively, $1 / S_{\mathrm{u}}$ and $1 / v_{\mathrm{su}}$ and their signs can be $(+,+),(0,+)$, $(-,+),(-, 0)$ and $(-,-)$ (cases $a, b, c, d$ and $e$, respectively). When $V_{1} K_{\mathrm{s} 2}=V_{2} K_{\mathrm{s} 1}$ the modifier $\mathrm{X}$ has no effect on LB straight line slopes and point $\mathrm{P}$ does not exist: lines pa and pi represent these type of cases when activation or inhibition is observed, respectively; both $V_{\max }$ and $K_{\mathrm{m}}$ are increased $\left(V_{2}>V_{1}\right.$; pa) or decreased $\left(V_{1}>V_{2}\right.$; pi) by $\mathrm{X}$, but the ratio $K_{\mathrm{m}} / V_{\max }$ is not changed. The broken lines (activation) and dotted lines (inhibition) represent $1 / v=f(1 /$ [S] ) at saturating [X]; the lines have a chemical meaning only when they are located in the first quadrant and so the lines starting in points $c, d$ and $e$ have to be extended to the right. In the cases represented on the Figure, the straight lines relative to $[\mathrm{X}] \neq 0$ are, generally, oblique; as $[\mathrm{X}]$ tends to saturation, they tend to a limit straight line that is also oblique, intercepting the vertical axis at $1 / v=1 / V_{2}$ and the horizontal axis at $1 /[\mathrm{S}]=-1 / K_{\mathrm{s} 2}$. However, when $K_{\mathrm{x} 1}=\infty$ (and so $K_{\mathrm{s} 2}=0$; case $A 3$, Fig. 2) the limit is a horizontal straight line and, in these cases, point $\mathrm{P}$ can be in the first quadrant $\left(V_{1}>V_{2}\right)$, on the vertical axis $\left(V_{1}=V_{2}\right)$ or in the second quadrant $\left(V_{2}>V_{1}\right)$. For details see text and Tables 2 and 5 .

tercept with the horizontal axis moves up to the origin of the axes $\left(1 / K_{\mathrm{s} 1}=0\right)$.

(3) When point $P$ is on the left of the vertical axis (cases $c, d$ and $e$ in Figs. 6, 7 and 8, and $c$ ' in Fig. 8) the situation is the one discussed in the preceding section under (3): $S_{\mathrm{u}}$ has a finite negative value. When $K_{\mathrm{s} 2}=K_{\mathrm{s} 1}$ point $\mathrm{P}$ is on 


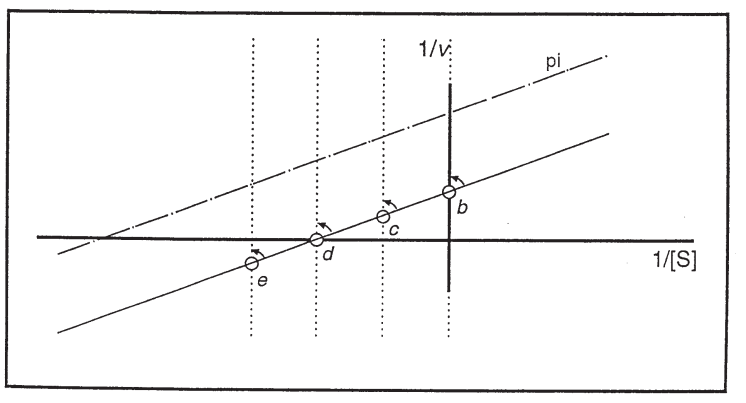

Figure 7. The crossing point $P$ in LineweaverBurk plots in the cases of total inhibition $\left(V_{2}=0\right.$ or $K_{\mathrm{x} 2}=\infty$ ).

The LB straight lines representing $1 / v=f(1 /$ [S] $)$ for $[\mathrm{X}]=0$ are always oblique and their slopes are positive; they are represented here by a continuous line. Generally, at a given set of constants, all the straight lines representing $1 / v=f(1 /[\mathrm{S}])$ at different $[\mathrm{X}]$ cross in one point $\mathrm{P}$. The $\mathrm{x}$ - and $\mathrm{y}$-coordinates of point $\mathrm{P}$ are $1 / S_{\mathrm{u}}$ and $1 / v_{\mathrm{su}}$, respectively, and their signs can be $(0,+)$, $(-,+),(-, 0)$, and (-,-) (cases $b, c, d$ and $e$, respectively). When $K_{\mathrm{x} 1}=\infty$ (and so $K_{\mathrm{s} 2}=0$; case A1, Fig. 2) $\mathrm{X}$ is an uncompetitive total inhibitor, it has no effect on LB straight line slopes and point $\mathrm{P}$ does not exist; in this case a finite value of $[\mathrm{X}]$ relates to the straight lines (pi) that are above and parallel to the line that represents $1 / v=f(1 /[\mathrm{S}])$ in absence of $\mathrm{X}$; at saturating [X] the line can not be drawn because it would intercept both the vertical $\left(1 / V_{2}=\infty\right)$ and horizontal axes $\left(-1 / K_{\mathrm{s} 2}=-\infty\right)$ at infinity. Apart from this case, when [X] increases the LB straight lines rotate counterclockwise about point $\mathrm{P}$, tending to vertical lines that intercept the horizontal axis at $1 /[\mathrm{S}]=-1 / K_{\mathrm{s} 2}$. The modifier $\mathrm{X}$ is a competitive total inhibitor in case $b$, a non-competitive total inhibitor in case $d$, and a mixed total inhibitor in cases $c$ and $e$. For details see text and Tables 2 and 5 .

the horizontal axis (cases $d$ ) and $\mathrm{X}$ changes $V_{\max }$, without affecting $K_{\mathrm{m}}$, and may be an inhibitor $\left(V_{1}>V_{2}\right)$ or an activator $\left(V_{2}>V_{1}\right)$; it is a non-competitive total inhibitor when $V_{2}=0$ (case $d$ in Fig. 7) and a particular type of essential activator when $V_{1}=0$ (case $d$ in Fig. 8). Point $\mathrm{P}$ is located in the second quadrant (cases $c$ and $c^{\prime}$ ) when, simultaneously, $V_{2} K_{\mathrm{s} 1}>$ $V_{1} K_{\mathrm{s} 2}, V_{2}>V_{1}$ and $K_{\mathrm{s} 1}>K_{\mathrm{s} 2}$ or when, simultaneously, $V_{1} K_{\mathrm{s} 2}>V_{2} K_{\mathrm{s} 1}, V_{1}>V_{2}$ and $K_{\mathrm{s} 2}>K_{\mathrm{s} 1}$ (see eqns. 8 and 13) excluding, obviously, the possibilities $K_{\mathrm{s} 1}=\infty$ and $K_{\mathrm{s} 2}=\infty$ that make $S_{\mathrm{u}}=\infty$. Point $\mathrm{P}$ is located in the third quad- rant (cases $e$ ) when, simultaneously, $V_{2} K_{\mathrm{s} 1}>$ $V_{1} K_{\mathrm{s} 2}, V_{2}>V_{1}$ and $K_{\mathrm{s} 2}>\mathrm{K}_{\mathrm{s} 1}$ or when, simultaneously, $V_{1} K_{\mathrm{s} 2}>V_{2} K_{\mathrm{s} 1}, V_{1}>V_{2}$ and $K_{\mathrm{s} 1}>K_{\mathrm{s} 2}$ (see eqns. 8 and 13). The effect of $\mathrm{X}$ on $V_{\max }$ and $K_{\mathrm{m}}$ (or on the intercepting points of the LB straight lines with the vertical and horizontal axes) depends, as in all cases, on the differences $\left(V_{2}-V_{1}\right)$ and $\left(K_{\mathrm{s} 2}-K_{\mathrm{s} 1}\right)$, respectively.

(4) When there is no point $P$ because the LB straight lines are parallel (cases pi and pa in Fig. 6 and pi in Fig. 7) the situation is that discussed in the preceding section under (4): $S_{\mathrm{u}}$ does not exist. The slope of the LB straight line is not affected by $\mathrm{X}$ when $V_{1} K_{\mathrm{s} 2}=V_{2} K_{\mathrm{s} 1}$ (see eqn. 12a) including the particular case when, simultaneously, $V_{2}=0$ and $K_{\mathrm{s} 2}=0$ (see eqn. 12). When $V_{2}>V_{1}$ and so $K_{\mathrm{s} 2}>K_{\mathrm{s} 1}$, the effect of $\mathrm{X}$ is to move down the LB straight line (not to rotate it) so that the intercepting points with the horizontal and the vertical axes approach to the origin of the axes: the values of $V_{\max }$ and $K_{\mathrm{m}}$ are increased by X. As $K_{\mathrm{s} 2} \neq \infty$, the point $(0,0)$ is never reached. When $V_{1}>V_{2}$ and so $K_{\mathrm{s} 1}>K_{\mathrm{s} 2}$, the effect of $\mathrm{X}$ is to move up the LB straight line so that the intercepting points with the horizontal and the vertical axes move away from the origin of the axes: the values of $V_{\max }$ and $K_{\mathrm{m}}$ are decreased by $\mathrm{X}$.

The situation $K_{\mathrm{x} 1}=\infty$ (and so $K_{\mathrm{s} 2}=0$; case $A$, Fig. 2) deserves particular comments. When $V_{1}=0$, case $c$ ' of Fig. 8 is produced; when both $V_{1}$ and $V_{2} \neq 0$, cases $a, b$ or $c$ of Fig. 6 can be produced depending on the difference $\left(V_{1}-V_{2}\right)$. The signs of the coordinates of point $\mathrm{P}$ are $(+,+)$ when $V_{1}>V_{2}$ (case $\alpha$ ); they are $(0,+)$ when $V_{1}=V_{2}$ (case $b$ ); they are $(-,+)$ when $V_{2}>V_{1}$ (cases $c$ or $c^{\prime}$ ). Here the plots $-1 / K_{\mathrm{m}}$ versus $[\mathrm{X}]$ are not hyperbolic but linear (see Table 2); in the limit situation when the $[\mathrm{X}]$ is saturating the LB straight line is parallel to the horizontal axis with equation $1 / v=1 / V_{2}$, and the value of $K_{\mathrm{m}}$ is zero $\left(K_{\mathrm{s} 2}=0\right)$. The horizontal lines discussed in this paragraph have not been represented in Fig. 6 not to overload it. When $V_{2}=0, \mathrm{X}$ is an 


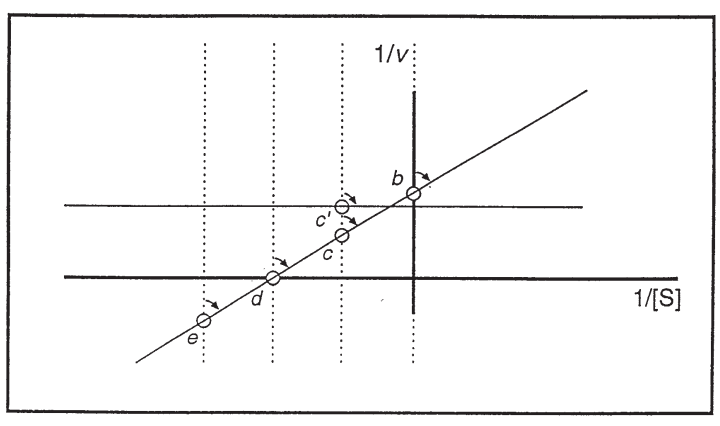

Figure 8. The crossing point $\mathbf{P}$ in LineweaverBurk plots in the cases of essential activation ( $V_{1}$ $=0$ or $K_{\mathrm{s} 1}=\infty$ ).

The LB straight lines representing $1 / v=f(1 /[\mathrm{S}])$ for [X] $=0$ would be depicted by vertical lines (dotted lines here) which intercept the horizontal axis at $1 /[\mathrm{S}]=$ $-1 / K_{\mathrm{s} 1}$; as $[\mathrm{X}]$ tends to zero the slope tends to infinity (see Table 5). The increase of [X] up to saturation makes the lines to rotate clockwise about point $\mathrm{P}$ up to an oblique line (in cases $b, c, d$ and $e$ ) or a horizontal one

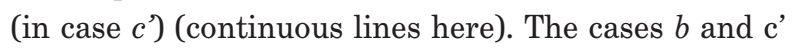
are produced when the mechanism is sequential: case $b$ when $\mathrm{X}$ binds first to the enzyme $\left(K_{\mathrm{s} 1}=\infty\right.$ and $K_{\mathrm{x} 2}=0$; case $C$, Fig. 2) and case $c^{\prime}$ when $\mathrm{S}$ binds first to the enzyme $\left(K_{\mathrm{x} 1}=\infty\right.$ and $K_{\mathrm{s} 2}=0$; case $A 2$, Fig. 2$)$. In the case $b$ the only effect of increasing [X] is to decrease the $K_{\mathrm{m}}$ and, in consequence the values of [S] that would be considered saturating. When the mechanism is random, and so both $K_{\mathrm{s} 1}$ and $K_{\mathrm{s} 2}$ are finite and positive, cases $c\left(K_{\mathrm{s} 1}>\mathrm{K}_{\mathrm{s} 2}\right), d\left(K_{\mathrm{s} 1}=K_{\mathrm{s} 2}\right)$ and $e\left(K_{\mathrm{s} 2}>K_{\mathrm{s} 1}\right)$ would be produced. The cases considered in this Figure can also represent bisubstrate enzyme reactions if both $\mathrm{X}$ and $\mathrm{S}$ are considered substrates. For details see text and Tables 2 and 5. Two discrepancies were noticed between our results (Figs. 6-8) and those reported by Frieden [16]; but, most probably they are due to typographic errors; as it would be prolix to explain the details, we are just stating what, in our opinion, would be the correct propositions of Frieden's paper: in page 3523, column 1, line 26 "Figs. $1 \mathrm{~A}$ and $3 \mathrm{~A}$, B, and C" should be "Fig. 3A, B, C, and D"; in page 3523, column 2, line 11 "Figs. $2 \mathrm{~B}$ and $3 \mathrm{C}, \mathrm{D}$, and E" should be "Fig. 1B and 3C, D, and E".

uncompetitive total inhibitor, the straight lines relative to different concentrations of $\mathrm{X}$ are parallel (pi in Fig. 7), the plots $-1 / K_{\mathrm{m}}$ versus $[\mathrm{X}]$ are linear (see Table 2), and the LB straight line corresponding to saturating [X] could not be drawn because it would intercept both the vertical $\left(V_{2}=0\right)$ and horizontal axes $\left(-1 / K_{\mathrm{s} 2}=-\infty\right)$ at infinity.

\section{THE DEGREE OF EFFECT (ACTI- VATION OR INHIBITION) AND $K_{\mathrm{e}}$}

The degree of effect of $\mathrm{X}$ on the reaction rate $(\varepsilon)$ is the ratio $\left(v-v_{\mathrm{x} 0}\right) / v_{\mathrm{xo}}$. The degree of effect is positive when $\mathrm{X}$ acts as an activator $(v>$ $v_{\mathrm{xo}}$ ) and, in this case, the expression degree of activation could be used. When $\mathrm{X}$ acts as an inhibitor $\left(v_{\mathrm{xo}}>v\right)$ the degree of effect is negative and in this case the expression degree of inhibition could be used: the value of the degree of inhibition is the modulus of the degree of effect and so it is also a positive value. The degrees of activation and inhibition can be expressed as percentages. The concept of degree of effect does not make sense when $\mathrm{X}$ is an essential activator $\left(V_{1}=0\right.$ or $\left.K_{\mathrm{s} 1}=\infty\right)$, because $\varepsilon$ always equals infinity when $v_{\text {хо }}=0$. From eqn. (2):

$\varepsilon=\frac{\frac{V_{\mu}}{v_{x o}}[\mathrm{X}]}{K_{c}+[\mathrm{X}]}$

where $V_{\mu} / v_{\mathrm{xo}}$, the value of $\varepsilon$ at saturating [X] can be deduced from eqns. (3) and (4) (see Appendix B) as follows:

$\frac{V_{\mu}}{v_{x o}}=\frac{V_{2} K_{s 1}-V_{1} K_{s 2}}{V_{1} K_{s 2}}+\frac{\frac{V_{2}\left(K_{s 2}-K_{s 1}\right)}{V_{1} K_{s 2}}[\mathrm{~S}]}{K_{s 2}+[\mathrm{S}]}$

and $K_{\mathrm{e}}$ is described by eqns. (5) and (5a) (see ref. [17]):

$K_{e}=K_{x 1}+\frac{\left(K_{x 2}-K_{x 1}\right)[\mathrm{S}]}{K_{s 2}+[\mathrm{S}]}$

Equation (14) shows that the plot $\varepsilon$ versus [X] is, in general, a rectangular hyperbola that in- 
Table 5. Formulas for $K_{\mathrm{m}} / V_{\max }$ and $1 / V_{\max }$ in particular cases of the rapid equilibrium model

\begin{tabular}{|c|c|c|c|}
\hline Class & Subclass & $K_{\mathrm{m}} / V_{\max }$ & $1 / V_{\max }$ \\
\hline \multirow[t]{5}{*}{$\begin{array}{c}V_{1} \neq 0 \\
\text { and } \\
V_{2} \neq 0\end{array}$} & more general & $\frac{K_{\mathrm{s} 1}}{V_{1}}+\frac{\frac{V_{1} K_{\mathrm{s} 2}-V_{2} K_{\mathrm{s} 1}}{V_{1} V_{2}}[\mathrm{X}]}{\frac{V_{1} K_{\mathrm{x} 2}}{V_{2}}+[\mathrm{X}]}$ & \multirow[t]{3}{*}{$\frac{1}{V_{1}}+\frac{\frac{V_{1}-V_{2}}{V_{1} V_{2}}[\mathrm{X}]}{\frac{V_{1} K_{\mathrm{x} 2}}{V_{2}}+[\mathrm{X}]}$} \\
\hline & $\begin{array}{c}K_{\mathrm{x} 1}=\infty \text { and } \\
K_{\mathrm{s} 2}=0\end{array}$ & $\frac{\frac{K_{\mathrm{s} 1} K_{\mathrm{x} 2}}{V_{2}}}{\frac{V_{1} K_{\mathrm{x} 2}}{V_{2}}+[\mathrm{X}]}$ & \\
\hline & $\begin{array}{l}V_{1} K_{\mathrm{s} 2}=V_{2} K_{\mathrm{s1}} \\
V_{1} K_{\mathrm{x} 2}=V_{2} K_{\mathrm{x} 1}\end{array}$ & $\frac{K_{\mathrm{s} 1}}{V_{1}}$ & \\
\hline & $\begin{array}{l}V_{1}=V_{2}=V \\
\text { more general }\end{array}$ & $\frac{K_{\mathrm{s} 1}}{V}+\frac{\frac{K_{\mathrm{s} 2}-K_{\mathrm{s} 1}}{V}[\mathrm{X}]}{K_{\mathrm{x} 2}+[\mathrm{X}]}$ & \multirow[t]{2}{*}{$\frac{1}{V}$} \\
\hline & $\begin{array}{c}V_{1}=V_{2}=V \text { and } \\
K_{\mathrm{x} 1}=\infty \text { and } \\
K_{\mathrm{s} 2}=0\end{array}$ & $\frac{\frac{K_{\mathrm{s} 1} K_{\mathrm{x} 2}}{V}}{K_{\mathrm{x} 2}+[\mathrm{X}]}$ & \\
\hline \multirow[t]{3}{*}{$V_{2}=0$} & more general & $\frac{K_{\mathrm{s} 1}}{V_{1}}+\frac{K_{\mathrm{s} 2}}{V_{1} K_{\mathrm{x} 2}}[\mathrm{X}]$ & \multirow[t]{2}{*}{$\frac{1}{V_{1}}+\frac{1}{V_{1} K_{\mathrm{x} 2}}[\mathrm{X}]$} \\
\hline & $\begin{array}{c}K_{\mathrm{x} 1}=\infty \text { and } \\
K_{\mathrm{s} 2}=0\end{array}$ & $\frac{K_{\mathrm{sl}}}{V_{1}}$ & \\
\hline & $\begin{array}{c}K_{\mathrm{x} 2}=\infty \text { and } \\
K_{\mathrm{s} 2}=\infty\end{array}$ & $\frac{K_{\mathrm{s} 1}}{V_{1}}+\frac{K_{\mathrm{s} 1}}{V_{1} K_{\mathrm{x} 1}}[\mathrm{X}]$ & $\frac{1}{V_{1}}$ \\
\hline \multirow[t]{3}{*}{$V_{1}=0$} & $\begin{array}{c}K_{\mathrm{s1}}=\infty \text { and } \\
K_{\mathrm{x} 2}=0\end{array}$ & \multirow[t]{2}{*}{$\frac{K_{\mathrm{s} 2} K_{\mathrm{x} 1}+K_{\mathrm{s} 2}[\mathrm{X}]}{V_{2}[\mathrm{X}]}$} & $\frac{1}{V_{2}}$ \\
\hline & more general & & \multirow[t]{2}{*}{$\frac{K_{\mathrm{x} 2}+[\mathrm{X}]}{V_{2}[\mathrm{X}]}$} \\
\hline & $\begin{array}{c}K_{\mathrm{x} 1}=\infty \text { and } \\
K_{\mathrm{s} 2}=0\end{array}$ & $\frac{K_{\mathrm{s1}} K_{\mathrm{x} 2}}{V_{2}[\mathrm{X}]}$ & \\
\hline
\end{tabular}

$K_{\mathrm{m}} / V_{\max }$ is the value of the slope of a Lineweaver-Burk straight line; $1 / V_{\max }$ is the value of the ordinate of the intercept with the vertical axis (for short, vertical intercept). Classes are defined in Table 1 . When $\mathrm{X}$ is a partial inhibitor or a non-essential activator (Class $V_{1} \neq 0$ and $V_{2} \neq 0$ ) both the plots slope versus [X] and vertical intercept versus [X] are, in general, rectangular hyperbolas intercepting the vertical axis at, $K_{\mathrm{s} 1} / V_{1}$ and $1 / V_{1}$, respectively; the horizontal asymptote of the plot slope versus [X] coincides with the horizontal axis when $K_{\mathrm{x} 1}=\infty$ (and so $K_{\mathrm{s} 2}=0$ ). The plots slope versus [X] and vertical intercept versus [X] are straight lines parallel to the horizontal axis when $V_{1} K_{\mathrm{s} 2}=V_{2} K_{\mathrm{s} 1}$ and $V_{1}=V_{2}$, respectively. When $\mathrm{X}$ is a total inhibitor (Class $V_{2}=0$ ) each plot is always a straight line, in general, a positive slope straight line. A horizontal straight line is observed in the case of uncompetitive total inhibition $\left(K_{\mathrm{x} 1}=\infty\right.$ and $\left.K_{\mathrm{s} 2}=0\right)$ for the plot slope versus [X] and in competitive total inhibition $\left(K_{\mathrm{x} 2}=\infty\right.$ and $\left.K_{\mathrm{s} 2}=\infty\right)$ for the plot vertical intercept versus [X]. When $\mathrm{X}$ is an essential activator (Class $V_{1}=0$ ) both plots are, in general, rectangular hyperbolas, the vertical axis itself being the vertical asymptote and the horizontal one a straight line above the horizontal axis. When the order of binding of $\mathrm{S}$ and $\mathrm{X}$ to the enzyme is not random there are exceptions: when $\mathrm{S}$ binds first $\left(K_{\mathrm{x} 1}=\infty\right.$ and $\left.K_{\mathrm{s} 2}=0\right)$ the plot slope versus $[\mathrm{X}]$ is a rectangular hyperbola but both asymptotes coincide with the axes; when X binds first $\left(K_{\mathrm{s} 1}=\infty\right.$ and $\left.K_{\mathrm{x} 2}=0\right)$, the plot vertical intercept versus $[\mathrm{X}]$ is a horizontal straight line.

tercepts the origin of the axes, being the equation for the horizontal asymptote $v=V_{\mu} / v_{\text {xo }}$ and the one for the vertical asymptote $[\mathrm{X}]=-K_{\mathrm{e}}$.

In general, the values of both $V_{\mu} / v_{\mathrm{xo}}$ and $K_{\mathrm{e}}$ depend on [S]. Formulas for $K_{\mathrm{e}}$ and $V_{\mu} / v_{\text {xо }}$ in particular cases are presented, respectively, in Tables 2 and 6.

Considering also the possibility of $\mathrm{X}$ being an essential activator, the value of $K_{\mathrm{e}}$, in more general terms, can be defined as the concentration of modifier at which, at a particular 


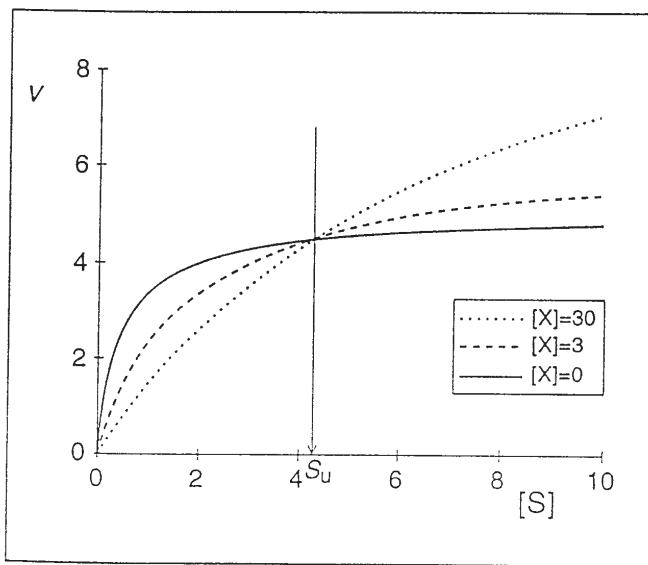

Figure 9. Plots $v$ versus [S] when $\mathrm{X}$ acts as an activator or an inhibitor depending on the concentration of substrate (i.e. $S_{\mathrm{u}}$ has a finite positive value).

As an example we have chosen the case when $V_{2}>V_{1}$ and $V_{1} K_{\mathrm{s} 2}>V_{2} K_{\mathrm{s} 1}$; with $V_{1}=5, V_{2}=20, K_{\mathrm{s} 1}=0.5, K_{\mathrm{s} 2}=$ $15, K_{\mathrm{x} 1}=1$, and $K_{\mathrm{x} 2}=30$ (arbitrary units). The continuous line represents the plot for $[\mathrm{X}]=0$, the broken one the plot for $[\mathrm{X}]=3$, and the dotted one the plot for $[\mathrm{X}]=$ 30 ; the values of $V_{\max }$ and $K_{\mathrm{m}}$ for these plots are, respectively, (5 and 0.5), (6.36 and 1.82), and (12.50 and 7.75). Both $V_{\max }$ and $K_{\mathrm{m}}$ are increased by $\mathrm{X}$ in such a way that a positive value for $S_{\mathrm{u}}$ is produced; the value of $S_{\mathrm{u}}$ can be calculated using eqn. (8) and in this case it is 4.33. $\mathrm{X}$ is an activator when [S] $>S_{\mathrm{u}}$ and an inhibitor when $[\mathrm{S}]<S_{\mathrm{u}}$

concentration of $\mathrm{S}$, the increase or decrease in the reaction rate is half of that achieved with saturating concentrations of $\mathrm{X}$ (see eqn. 2). The symbols $K_{\mathrm{i}}$ and $K_{\mathrm{a}}$ could be used when X acts, respectively, as an inhibitor or an activator.

Equation (5) shows that the value of $K_{\mathrm{e}}$ is a sort of pondered mean of $K_{\mathrm{x} 1}$ and $K_{\mathrm{x} 2}, K_{\mathrm{s} 2}$ and [S] being the pondering factors to be applied to $K_{\mathrm{x} 1}$ and $K_{\mathrm{x} 2}$, respectively.

The plot $K_{\mathrm{e}}$ versus [S] is, in general, a rectangular hyperbola that intercepts the vertical axis at $K_{\mathrm{e}}=K_{\mathrm{x} 1}, K_{\mathrm{e}}=K_{\mathrm{x} 2}$ and $[\mathrm{X}]=-K_{\mathrm{s} 2}$ (eqn. 5 a) being the equations for the horizontal and vertical asymptotes, respectively: as expected the possible aspects of this plot are the same as those for $K_{\mathrm{m}}$ versus [X] (Fig. 5). In the cases $b, c, d$, and $e$ the two graphs (Figs. 5A and 5B) correspond to the same situations, because $K_{\mathrm{s} 2}=\infty$ is equivalent to $K_{\mathrm{x} 2}=\infty, K_{\mathrm{s} 2}>K_{\mathrm{s} 1}$ equivalent to $K_{\mathrm{x} 2}>K_{\mathrm{x} 1}, K_{\mathrm{s} 1}=K_{\mathrm{s} 2}$ equivalent to $K_{\mathrm{x} 1}=K_{\mathrm{x} 2}$, and $K_{\mathrm{s} 1}>K_{\mathrm{s} 2}$ equivalent to $K_{\mathrm{x} 1}>$ $K_{\mathrm{x} 2}$. The cases $a$ and $f$ in Fig. 5 A correspond to the cases $f$ and $a$ in Fig. 5B, respectively, because $K_{\mathrm{s} 1}=\infty$ is equivalent to $K_{\mathrm{x} 2}=0$ and $K_{\mathrm{s} 2}=0$ equivalent to $K_{\mathrm{x} 1}=\infty$.

Both eqns. (2) and (14) can be rearranged into a linear form:

$\frac{1}{\left(v-v_{x o}\right)}=\frac{1}{V_{\mu}}+\frac{K_{e}}{V_{\mu}} \frac{1}{[\mathrm{X}]}$

$\frac{v_{x o}}{\left(v-v_{x o}\right)}=\frac{v_{x o}}{V_{\mu}}+\frac{v_{x o} K_{e}}{V_{\mu}} \frac{1}{[\mathrm{X}]}$

The plots $1 /\left(v-v_{\mathrm{xo}}\right)$ versus $1 /[\mathrm{X}]$ and $v_{\mathrm{xo}} /\left(v-v_{\mathrm{xo}}\right)$ versus $1 /[\mathrm{X}]$ are both linear and, in both cases, the value of the abscissa at the intercept of these plots with the horizontal axis is $-1 / K_{\mathrm{e}}$. So, the value of $K_{\mathrm{e}}$ can be graphically evaluated.

When $\mathrm{X}$ is a total inhibitor $\left(V_{2}=0\right.$ or $K_{\mathrm{x} 2}=\infty$ ), $\mathrm{I}_{50}$ and $\mathrm{I}_{50 \text { (sat), the concentration of }}$ inhibitor required to inhibit by $50 \%$ the reaction rate at a determined concentration of $\mathrm{S}$ and at saturating concentration of S [14] are, respectively, equivalent to $K_{\mathrm{e}}$ and $K_{\mathrm{x} 2}$.

From eqns. (5) or (5a) and the definitions of the dissociation constants it can be deduced that $K_{\mathrm{e}}$ is a sort of equilibrium constant for the dissociation of $\mathrm{X}$ from the enzyme complexes containing $\mathrm{X}(\mathrm{EX}+\mathrm{ESX} \leftrightarrow \mathrm{E}+\mathrm{ES}+\mathrm{X})$.

$K_{e}=\frac{[\mathrm{X}]([\mathrm{E}]+[\mathrm{ES}])}{[\mathrm{EX}]+[\mathrm{ESX}]}$

Note that the denominator of eqn. (5b) is the sum of the concentrations of the enzyme complexes containing $\mathrm{X}$, and the numerator is the product of [X] by the sum of the concen- 
Table 6. Formulas for $V_{\mu} / v_{\mathrm{xo}}, \varepsilon_{\mathrm{so}}$ and $\mathrm{E}_{\mathrm{s}}$ in particular cases of the rapid equilibrium model

\begin{tabular}{|c|c|c|c|c|}
\hline Class & Subclass & $V_{\mu} / v_{\mathrm{xo}}$ & $\varepsilon_{\text {so }}$ & $\boldsymbol{E}_{\sigma}$ \\
\hline \multirow[t]{6}{*}{$\begin{array}{l}V_{1} \neq 0 \\
\text { and } \\
V_{2} \neq 0\end{array}$} & more general & $\frac{V_{2} K_{\mathrm{s}}-V_{1} K_{\mathrm{s} 2}}{V_{1} K_{\mathrm{s} 2}}+\frac{\frac{V_{2}\left(K_{\mathrm{s} 2}-K_{\mathrm{s} 1}\right)}{V_{1} K_{\mathrm{s} 2}}[\mathrm{~S}]}{K_{\mathrm{s} 2}+[\mathrm{S}]}$ & $\frac{\frac{V_{2} K_{\mathrm{s1}}-V_{1} K_{\mathrm{s} 2}}{V_{1} K_{\mathrm{s} 2}}[\mathrm{X}]}{K_{\mathrm{x} 1}+[\mathrm{X}]}$ & $\frac{\left(K_{\mathrm{s} 2}-K_{\mathrm{s} 1}\right)\left(V_{2}[\mathrm{X}]^{2}+V_{1} K_{\mathrm{x} 2}[\mathrm{X}]\right)}{V_{1} K_{\mathrm{s} 2}\left(K_{\mathrm{x} 2}+[\mathrm{X}]\right)\left(K_{\mathrm{x} 1}+[\mathrm{X}]\right)}$ \\
\hline & $\begin{array}{c}K_{\mathrm{x} 1}=\infty \text { and } \\
K_{\mathrm{s} 2}=0\end{array}$ & $\frac{V_{2} K_{\mathrm{s} 1}+\left(V_{2}-V_{1}\right)[\mathrm{S}]}{V_{1}[\mathrm{~S}]}$ & $\frac{V_{2}[\mathrm{X}]}{V_{1} K_{\mathrm{x} 2}}$ & $\frac{-\left(V_{2}[\mathrm{X}]^{2}+V_{1} K_{\mathrm{x} 2}[\mathrm{X}]\right)}{V_{1} K_{\mathrm{x} 2}\left(K_{\mathrm{x} 2}+[\mathrm{X}]\right)}$ \\
\hline & $\begin{array}{l}K_{\mathrm{s} 1}=K_{\mathrm{s} 2}=K_{\mathrm{s}} \\
K_{\mathrm{x} 1}=K_{\mathrm{x} 2}=K_{\mathrm{x}}\end{array}$ & $\frac{V_{2}-V_{1}}{V_{1}}$ & $\frac{\frac{V_{2}-V_{1}}{V_{1}}[\mathrm{X}]}{K_{\mathrm{x}}+[\mathrm{X}]}$ & 0 \\
\hline & $\begin{array}{l}V_{1} K_{\mathrm{s} 2}=V_{2} K_{\mathrm{s} 1} \\
V_{1} K_{\mathrm{x} 2}=V_{2} K_{\mathrm{x} 1}\end{array}$ & $\frac{\frac{V_{2}-V_{1}}{V_{1}}[\mathrm{~S}]}{K_{\mathrm{s} 2}+[\mathrm{S}]}$ & 0 & $\frac{\frac{K_{\mathrm{s} 2}-K_{\mathrm{s} 1}}{K_{\mathrm{s} 1}}[\mathrm{X}]}{K_{\mathrm{x} 2}+[\mathrm{X}]}$ \\
\hline & $\begin{array}{c}V_{1}=V_{2}=V \\
\text { more general }\end{array}$ & $\frac{K_{\mathrm{s} 1}-K_{\mathrm{s} 2}}{K_{\mathrm{s} 2}+[\mathrm{S}]}$ & $\frac{\frac{K_{\mathrm{s} 1}-K_{\mathrm{s} 2}}{K_{\mathrm{s} 2}}[\mathrm{X}]}{K_{\mathrm{x} 1}+[\mathrm{X}]}$ & $\frac{\frac{K_{\mathrm{s} 2}-K_{\mathrm{s} 1}}{K_{\mathrm{s} 2}}[\mathrm{X}]}{K_{\mathrm{x} 1}+[\mathrm{X}]}$ \\
\hline & $\begin{aligned} V_{1}=V_{2} & =V \\
\text { and } K_{\mathrm{x} 1} & =\infty \\
\text { and } K_{\mathrm{s} 2} & =0\end{aligned}$ & $\frac{K_{\mathrm{s} 1}}{[\mathrm{~S}]}$ & $\frac{[\mathrm{X}]}{K_{\mathrm{x} 2}}$ & $\frac{-[\mathrm{X}]}{K_{\mathrm{x} 2}}$ \\
\hline \multirow[t]{4}{*}{$V_{2}=0$} & more general & \multirow[t]{4}{*}{-1} & \multirow[t]{2}{*}{$\frac{-[\mathrm{X}]}{K_{\mathrm{x} 1}+[\mathrm{X}]}$} & $\frac{\left(K_{\mathrm{x} 2}-K_{\mathrm{x} 1}\right)[\mathrm{X}]}{\left(K_{\mathrm{x} 2}+[\mathrm{X}]\right)\left(K_{\mathrm{x} 1}+[\mathrm{X}]\right)}$ \\
\hline & $\begin{array}{c}K_{\mathrm{x} 2}=\infty \text { and } \\
K_{\mathrm{s} 2}=\infty\end{array}$ & & & $\frac{[\mathrm{X}]}{K_{\mathrm{x} 1}+[\mathrm{X}]}$ \\
\hline & $\begin{array}{c}K_{\mathrm{x} 1}=\infty \text { and } \\
K_{\mathrm{s} 2}=0\end{array}$ & & 0 & $\frac{-[\mathrm{X}]}{K_{\mathrm{x} 2}+[\mathrm{X}]}$ \\
\hline & $\begin{array}{l}K_{\mathrm{s} 1}=K_{\mathrm{s} 2}=K_{\mathrm{s}} \\
K_{\mathrm{x} 1}=K_{\mathrm{x} 2}=K_{\mathrm{x}}\end{array}$ & & $\frac{-[\mathrm{X}]}{K_{\mathrm{x}}+[\mathrm{X}]}$ & 0 \\
\hline
\end{tabular}

$\mathrm{V}_{\mu} / v_{\mathrm{xo}}$ is the degree of effect $\left(\left(v-v_{\mathrm{xo}}\right) / v_{\mathrm{xo}}\right)$ of saturating [X], at a determined [S]; $\varepsilon_{\mathrm{so}}$ is the limit to which the degree of effect of a determined [X] tends, when [S] tends to zero; and $E_{\sigma}$ is the difference between two degrees of effect at a given [X]: those produced at saturating [S] and at $\varepsilon_{\mathrm{s} 0}$. Classes are defined in Table 1. $V_{\mu} / v_{\mathrm{xo}}$ has no dimensions because it is the quotient of two reaction rates, the difference between the reaction rates at saturating $[\mathrm{X}]$ and in the absence of $\mathrm{X}$, and the reaction rate in the absence of $\mathrm{X}:\left(v_{\mathrm{x} \infty}-v_{\mathrm{xo}}\right) / v_{\mathrm{xo}}$. Note that, unlike to the function $V_{\mu}=f([\mathrm{~S}])$, the function $V_{\mu} / v_{\mathrm{xo}}=f([\mathrm{~S}])$ is, in general, hyperbolic. The value of $V_{\mu} / v_{\text {xо }}$ varies between -1 and $\infty$ : it is -1 , i.e. $100 \%$ inhibition, in the cases when $\mathrm{X}$ is a total inhibitor (Class $V_{2}=0$ ); it would be infinity when $\mathrm{X}$ is an essential activator, because in these cases the reaction rate in the absence of $\mathrm{X}$ is zero. In all cases, $\varepsilon_{\text {so }}=0$ when $[\mathrm{X}]=0$. For $[\mathrm{X}] \neq 0$, the sense of $\varepsilon_{\mathrm{so}}$ deserves more comments. In the Lineweaver-Burk plots, the far right extremes $(1 /[\mathrm{S}] \rightarrow \infty)$ of the straight lines correspond to the limit to which $v$ tends when $[\mathrm{S}]$ tends to zero. When the LB straight lines relative to different [X] are parallel they would touch each other at infinity, i.e. $v-v_{\mathrm{xo}}=0$ when $1 /[\mathrm{S}] \rightarrow \infty$; so $\varepsilon_{\mathrm{so}}=0$ when $V_{1} K_{\mathrm{x} 2}=V_{2} K_{\mathrm{x} 1}$, including the case of uncompetitive total inhibition $\left(K_{\mathrm{x} 1}=\infty\right.$ and $\left.V_{2}=0\right)$. In all other cases, the points of the LB straight lines relative to $[\mathrm{X}]=0$ and $[\mathrm{X}] \neq 0$ walk apart when $1 /[\mathrm{S}]$ tends to infinity; i.e. $\varepsilon_{\mathrm{so}} \neq 0$. The sign of $\varepsilon_{\mathrm{so}}$ is negative when the extreme right of the LB straight lines relative to $[\mathrm{X}] \neq 0$ are located above the straight line relative to $[\mathrm{X}]=0$; in the opposite case, it is positive.

trations of the enzyme complexes not containing $\mathrm{X}$.

At saturating [S], only the complexes ESX and ES exist and so $K_{\mathrm{e}} \rightarrow K_{\mathrm{x} 2}$, the dissociation constant for the equilibrium ESX $\leftrightarrow$ ES + $\mathrm{X}$. As the concentration of $\mathrm{S}$ tends to zero the complexes ES and ESX tend to disappear and, at the limit, the only existing forms will be $\mathrm{E}$ and EX: $K_{\mathrm{e}} \rightarrow K_{\mathrm{x} 1}$, the dissociation constant for the equilibrium $\mathrm{EX} \leftrightarrow \mathrm{E}+\mathrm{X}$.

A similar reasoning can be applied to the limiting cases presented in Fig. 2. In the cases $A$ $\left(K_{\mathrm{x} 1}=\infty\right), K_{\mathrm{e}}$ tends to a finite value $\left(K_{\mathrm{x} 2}\right)$ at saturating [S], and tends to infinity as [S] approaches zero; in the cases $B\left(\mathrm{~K}_{\mathrm{x} 2}=\infty\right)$ and $C$ $\left(K_{\mathrm{x} 2}=0\right) K_{\mathrm{e}}$ tends, respectively, to infinity 
and zero at saturating [S], and tends to a finite value $\left(K_{\mathrm{x} 1}\right)$ as [S] approaches zero.

The concept of $K_{\mathrm{e}}$ helps to clarify the meaning of saturating concentration of X. Strictly, speaking $[\mathrm{X}]$ is saturating when its value approaches infinity so that $v$ tends to $v_{\mathrm{xo}}+V_{\mu}$ (eqn. 2) and only the enzyme complexes containing $\mathrm{X}$ exist (Fig. 1). However, for a determined enzyme system and at a given concentration of substrate, [X] can be considered saturating when $[\mathrm{X}] \gg K_{\mathrm{e}}$ (see eqn. 2). As the value of $K_{\mathrm{e}}$ can vary between $K_{\mathrm{x} 1}$ (when [S] $\rightarrow$ 0 ) and $K_{\mathrm{x} 2}$ (when [S] $\rightarrow \infty$ ), a fixed concentration of $\mathrm{X}$ is saturating at any concentration of S only if, simultaneously, [X] $\gg K_{\mathrm{x} 1}$ and [X] > $K_{\mathrm{x} 2}$. Similarly, the concept of $K_{\mathrm{m}}$ helps to clarify the meaning of saturating concentration of S. Strictly speaking, [S] is saturating when its value approaches infinity so that $v$ tends to $V_{\max }$ (eqn. 9) and only the enzyme complexes containing S exist (Fig. 1). However, for a determined enzyme system and at a given concentration of substrate, [S] can be considered saturating when [S] $>K_{\mathrm{m}}$ (see eqn. 9). A fixed concentration of $\mathrm{S}$ is saturating at any concentration of $\mathrm{X}$ only if, simultaneously, [S] $>K_{\mathrm{s} 1}$ and [S] $>K_{\mathrm{s} 2}$.

Related to this, the limiting cases in Fig. 2 require some comments. In the case $A\left(K_{\mathrm{x} 1}=\infty\right.$ and $K_{\mathrm{s} 2}=0 ; \mathrm{S}$ binds first to the enzyme), when [X] tends to infinity, $K_{\mathrm{m}}$ tends to zero $\left(K_{\mathrm{s} 2}=0\right)$ and so, if $[\mathrm{S}]>\left[\mathrm{E}_{\mathrm{t}}\right], \mathrm{S}$ would almost saturate the enzyme, even if its concentration is very low; when [S] tends to zero, $K_{\mathrm{e}}$ tends to infinity $\left(K_{\mathrm{x} 1}=\infty\right)$ and so, at very low [S], X almost does not bind to the enzyme and, obviously, it is impossible to reach saturating concentrations of X. In this case there is no fixed concentration of $\mathrm{X}$ that could be considered saturating at all concentrations of S. In the case $B$ $\left(K_{\mathrm{x} 2}=\infty\right.$ and $K_{\mathrm{s} 2}=\infty$; competitive total inhibition), when [S] is saturating, $K_{\mathrm{e}}$ tends to infinity $\left(K_{\mathrm{x} 2}=\infty\right)$ and so X can not bind to the enzyme; when [X] is saturating, $K_{\mathrm{m}}$ tends to infinity $\left(K_{\mathrm{S} 2}=\infty\right)$ and so $\mathrm{S}$ can not bind to the enzyme. In this case there is neither a fixed concentration of $\mathrm{S}$ that could be considered saturating at all concentrations of $\mathrm{X}$, nor a fixed concentration of $\mathrm{X}$ that could be considered saturating at all concentrations of $\mathrm{S}$. In the case $C\left(K_{\mathrm{s} 1}=\infty\right.$ and $K_{\mathrm{x} 2}=0 ; \mathrm{X}$ is an essential activator that binds first to the enzyme), when [S] tends to infinity, $K_{\mathrm{e}}$ tends to zero $\left(K_{\mathrm{x} 2}=0\right)$ and so, if $[\mathrm{X}]>\left[\mathrm{E}_{\mathrm{t}}\right], \mathrm{X}$ would almost saturate the enzyme, even if its concentration is very low; when [X] tends to zero, $K_{\mathrm{m}}$ tends to infinity $\left(K_{\mathrm{S} 1}=\infty\right)$ and so $\mathrm{S}$ almost does not bind to the enzyme and, obviously, it is impossible to reach saturating concentrations of $\mathrm{S}$. In this case there is no fixed concentration of $\mathrm{S}$ that could be considered saturating at all concentrations of $\mathrm{X}$.

The relationship between the degree of effect of a fixed concentration of $\mathrm{X}$ and [S] is shown by eqn. (18) (see Appendix B):

$\varepsilon=\varepsilon_{s o}+\frac{E_{\sigma}[\mathrm{S}]}{K_{m}+[\mathrm{S}]}$

where

$\varepsilon_{s o}=\frac{\frac{V_{2} K_{s 1}-V_{1} K_{s 2}}{V_{1} K_{s 2}}[\mathrm{X}]}{K_{x 1}+[\mathrm{X}]}$

$E_{\sigma}=\frac{\frac{K_{s 2}-K_{s 1}}{K_{s 1}}[\mathrm{X}]}{K_{x 2}+[\mathrm{X}]} \frac{\alpha}{\beta}$

and

$\frac{\alpha}{\beta}=\frac{K_{x 2}+\frac{V_{2}}{V_{1}}[\mathrm{X}]}{K_{x 2}+\frac{K_{s 2}}{K_{s 1}}[\mathrm{X}]}$

Equation (18) shows that the plot $\varepsilon$ versus [S] is, in general, a rectangular hyperbola that intercepts the vertical axis at $\varepsilon=\varepsilon_{\text {so }}$, the equation for the horizontal asymptote being 
$\varepsilon=\varepsilon_{\mathrm{So}}+E_{\sigma}$ and that for the vertical asymptote $[\mathrm{S}]=-K_{\mathrm{m}}$.

$\varepsilon_{\mathrm{so}}$ is the limit to which the degree of effect of a determined [X] tends when [S] tends to zero. At a determined [X], $E_{\sigma}$ is the difference between the degree of effect at saturating concentrations of $\mathrm{S}\left(\varepsilon_{\mathrm{S} \infty}\right)$ and when $[\mathrm{S}] \rightarrow 0\left(\varepsilon_{\mathrm{So}}\right)$. $\alpha$ and $\beta$ are factors that can transform $V_{1}$ and $K_{\mathrm{s} 1}$ into $V_{\max }$ and $K_{\mathrm{m}}$, respectively [14, 15]. Formulas for $\varepsilon_{\text {so }}$ and $E_{\sigma}$ in particular cases are presented in Table 6 .

As the value of $\alpha / \beta$ is always positive (see eqn. 21) the sign of $E_{\sigma}$ depends only on the difference $\left(K_{\mathrm{s} 2}-K_{\mathrm{s} 1}\right)$ (see eqn. 20$)$.

(a) When $K_{\mathrm{s} 2}>K_{\mathrm{s} 1}, E_{\sigma}$ is positive and so the degree of effect of a fixed [X] increases with increasing values of [S] (see eqn. 18). If, at a determined [S], $\mathrm{X}$ acts as an activator, the increase of [S] increases the degree of activation. However, if X, at that particular [S], acts as an inhibitor, the increase of [S] decreases the degree of inhibition; this is also true when $\mathrm{X}$ is a competitive total inhibitor $\left(K_{\mathrm{s} 2}=\infty\right)$. When, simultaneously, $K_{\mathrm{s} 2}>K_{\mathrm{s} 1}, V_{1} K_{\mathrm{s} 2}>$ $V_{2} K_{\mathrm{s} 1}, V_{2}>V_{1}$ and $K_{\mathrm{s} 2} \neq \infty$, i.e. the value of $S_{\mathrm{u}}$ is finite and positive, the degree of effect is negative at [S] $<S_{\mathrm{u}}$ and, as [S] increases from values below $S_{\mathrm{u}}$ up to values above $S_{\mathrm{u}}$, it turns into positive.

(b) When $K_{\mathrm{s} 1}>K_{\mathrm{s} 2}, E_{\sigma}$ is negative and so the degree of effect of a fixed [X] decreases with increasing values of [S] (see eqn. 18). If, at a determined [S], $\mathrm{X}$ acts as an activator, the increase of [S] decreases the degree of activation. However, if X, at that particular [S], acts as an inhibitor, the increase of [S] increases the degree of inhibition. When, simultaneously, $K_{\mathrm{s} 1}>K_{\mathrm{s} 2}, V_{2} K_{\mathrm{s} 1}>V_{1} K_{\mathrm{s} 2}, V_{1}>V_{2}$ and $K_{\mathrm{s} 1} \neq \infty$, i.e. the value of $S_{\mathrm{u}}$ is finite and positive, the degree of effect is positive at [S] < $S_{\mathrm{u}}$ and, as [S] increases from values below $S_{\mathrm{u}}$ up to values above $S_{\mathrm{u}}$, it turns into negative.

(c) When $K_{\mathrm{s} 1}=K_{\mathrm{s} 2}, E_{\sigma}=0$ and so the degree of effect does not depend on [S]. From eqn. (18) one would assume that when $K_{\mathrm{m}} \rightarrow 0$ or $K_{\mathrm{m}} \rightarrow \infty$ also the value of the degree of effect is unaffected by changes in [S]. However, these situations arise when [X] is saturating and, respectively, $K_{\mathrm{s} 2}=0$ or $K_{\mathrm{s} 2}=\infty$ : in these cases (cases $A$ and $B$, Fig. 2), as stated above, there is no fixed concentration of $\mathrm{X}$ that could be considered saturating for all concentrations of S. So, the only situation when the value of the degree of effect is not changed when [S] changes is when $K_{\mathrm{s} 1}=K_{\mathrm{s} 2}$.

R.F. thanks the researchers of the Departments of Physiological Chemistry and Biochemistry (Universidade do Porto, Portugal) for facilitating his stay in Madrid. J.M.R. thanks Dr. J.C. Cameselle (Universidad de Extremadura, Spain) in whose laboratory part of this work was carried out. We thank Javier Pérez for technical assistance. 


\section{Appendix A: Consequences derived from equation (1)}

The relation between dissociation constants shown in eqn. (1) has many and important consequences. To state that $K_{\mathrm{s} 1}=K_{\mathrm{s} 2}$ is the $K_{m}=K_{s 1}+\frac{K_{s 1} \frac{K_{x 2}-K_{x 1}}{K_{x 1}}[\mathrm{X}]}{K_{x 2}+[\mathrm{X}]}$ same as to state that $K_{\mathrm{x} 1}=K_{\mathrm{x} 2} ; K_{\mathrm{s} 2}>K_{\mathrm{s} 1}$ is the same as $K_{\mathrm{x} 2}>K_{\mathrm{x} 1}$, and $V_{1} K_{\mathrm{s} 2}>V_{2} K_{\mathrm{s} 1}$ is the same as $V_{1} K_{\mathrm{x} 2}>V_{2} K_{\mathrm{x} 1}$. Based on eqn. (1) it can be demonstrated that most of the equations in this paper can be written in a differ$\frac{1}{v_{s u}}=\frac{K_{x 2}-K_{x 1}}{V_{1} K_{x 2}-V_{2} K_{x 1}}$ ent way: some examples are eqns. (5a), (8), (11a), (13), (19), and (20) that could have been written as in eqns. (5c), (8a), (11c), (13a), (19a), and (20a), respectively.

$K_{e}=K_{x 1}+\frac{K_{x 1} \frac{\left(K_{s 2}-K_{s 1}\right)}{K_{s 1}}[\mathrm{~S}]}{K_{s 2}+[\mathrm{S}]}$

$\mathrm{S}_{u}=\frac{K_{s 1}\left(V_{1} K_{x 2}-V_{2} K_{x 1}\right)}{K_{x 1}\left(V_{2}-V_{1}\right)}$

$$
E_{\sigma}=\frac{\frac{K_{x 2}-K_{x 1}}{K_{x 1}}[\mathrm{X}]}{K_{x 2}+[\mathrm{X}]} \frac{\alpha}{\beta}
$$

\section{Appendix B: Deduction of some of the equations in the main text}

B1. Deduction of eqn. (2) from eqn. (9)

$$
\begin{aligned}
& v=\frac{V_{1}[\mathrm{~S}]}{K_{s 1}+[\mathrm{S}]}+ \\
& +\frac{\frac{V_{2}[\mathrm{~S}] K_{x 2}\left(K_{s 1}+[\mathrm{S}]\right)-V_{1}[\mathrm{~S}] K_{x 2}\left(K_{s 2}+[\mathrm{S}]\right)}{K_{x 2}\left(K_{s 1}+[\mathrm{S}]\right)\left(K_{s 2}+[\mathrm{S}]\right)}}{\frac{K_{x 2}\left(K_{s 1}+[\mathrm{S}]\right)}{K_{s 2}+[\mathrm{S}]}+[\mathrm{X}]} \\
& v=\frac{V_{1}[\mathrm{~S}]}{K_{s 1}+[\mathrm{S}]}+
\end{aligned}
$$$$
v=\frac{\frac{V_{1} K_{x 2}+V_{2}[\mathrm{X}]}{K_{x 2}+[\mathrm{X}]}[\mathrm{S}]}{\frac{K_{s 1} K_{x 2}+K_{s 2}[\mathrm{X}]}{K_{x 2}+[\mathrm{X}]}+[\mathrm{S}]}
$$

and, using the mathematical procedure com-

$$
+\frac{\left(\frac{V_{2}[\mathrm{~S}]}{K_{s 2}+[\mathrm{S}]}-\frac{V_{1}[\mathrm{~S}]}{K_{s 1}+[\mathrm{S}]}\right)[\mathrm{X}]}{\frac{K_{\mathrm{x} 1} K_{s 2}+K_{x 2}[\mathrm{~S}]}{K_{s 2}+[\mathrm{S}]}}
$$


B2. Deduction of eqn. (11b) from eqn. (11) and the definitions of the equilibrium constants

$K_{m}=\frac{K_{s 1} K_{x 2}+K_{s 2}[\mathrm{X}]}{K_{x 2}+[\mathrm{X}]}$

$=\frac{\frac{[\mathrm{E}][\mathrm{S}][\mathrm{ES}][\mathrm{X}]}{[\mathrm{ES}][\mathrm{ESX}]}+\frac{[\mathrm{EX}][\mathrm{S}][\mathrm{X}]}{[\mathrm{ESX}]}}{\frac{[\mathrm{ES}][\mathrm{X}]}{[\mathrm{ESX}]}+[\mathrm{X}]}$

$[\mathrm{E}][\mathrm{S}]+[\mathrm{EX}][\mathrm{S}]$

$=\frac{[\mathrm{ESX}]}{\frac{[\mathrm{ES}]}{[\mathrm{ESX}]}+1}$

$K_{\mid m}=\frac{[\mathrm{S}]([\mathrm{E}]+[\mathrm{EX}])}{[\mathrm{ES}]+[\mathrm{ESX}]}$

B3. Deduction of eqn. (13) from eqns. (8) and (12)

$\mathrm{S}_{u}=\frac{V_{1} K_{s 1}-V_{2} K_{s 1}}{\mathrm{~V}_{2}-V_{1}}$

$$
\begin{aligned}
& \frac{1}{v}=\frac{K_{x 2}+[\mathrm{X}]}{V_{1} K_{x 2}+V_{2}[\mathrm{X}]}+ \\
& +\frac{K_{s 1} K_{x 2}+K_{s 2}[\mathrm{X}]}{V_{1} K_{x 2}+V_{2}[\mathrm{X}]} \frac{1}{[\mathrm{~S}]}
\end{aligned}
$$

$$
\begin{aligned}
& \frac{1}{v_{s u}}=\frac{K_{x 2}+[\mathrm{X}]}{V_{1} K_{x 2}+V_{2}[\mathrm{X}]}+ \\
& +\frac{K_{s 1} K_{x 2}+K_{s 2}[\mathrm{X}]}{V_{1} K_{x 2}+V_{2}[\mathrm{X}]} \frac{\left(V_{2}-V_{1}\right)}{V_{1} K_{s 2}-V_{2} K_{s 1}}
\end{aligned}
$$

$$
\begin{aligned}
& =\frac{V_{1} K_{x 2}\left(K_{s 2}-K_{s 1}\right)+V_{2}[\mathrm{X}]\left(K_{s 2}-K_{s 1}\right)}{\left(V_{1} K_{x 2}+V_{2}[\mathrm{X}]\right)\left(V_{1} K_{x 2}-V_{2} \mathrm{~K}_{\mathrm{s} 1}\right)} \\
& \frac{1}{v_{s u}}=\frac{K_{s 2}-K_{s 1}}{V_{1} K_{s 2}-V_{2} K_{s 1}}
\end{aligned}
$$

B4. Deduction of eqn. (15) from eqns. (3) and (4)

$$
\frac{V_{\mu}}{v_{x o}}=\frac{\frac{V_{2}[\mathrm{~S}]}{K_{s 2}+[\mathrm{S}]}-\frac{V_{1}[\mathrm{~S}]}{K_{s 1}+[\mathrm{S}]}}{\frac{V_{1}[\mathrm{~S}]}{K_{s 1}+[\mathrm{S}]}}
$$

$$
\begin{aligned}
= & \frac{V_{2}[\mathrm{~S}]\left(K_{s 1}+[\mathrm{S}]\right)-V_{1}[\mathrm{~S}]\left(K_{s 2}+[\mathrm{S}]\right)}{\left(K_{s 1}+[\mathrm{S}]\right)\left(K_{s 2}+[\mathrm{S}]\right)} \\
\frac{V_{1}[\mathrm{~S}]\left(K_{s 2}+[\mathrm{S}]\right)}{\left(K_{s 1}+[\mathrm{S}]\right)\left(K_{s 2}+[\mathrm{S}]\right)} & \frac{\left(V_{2} K_{s 1}-V_{1} K_{s 2}\right)+\left(V_{2}-V_{1}\right)[\mathrm{S}]}{\mathrm{V}_{1} K_{s 2}+V_{1}[\mathrm{~S}]}
\end{aligned}
$$

and, using the mathematical procedure described in the companion paper [17]:

$$
\begin{aligned}
& \frac{V_{\mu}}{v_{x o}}=\frac{V_{2} K_{s 1}-V_{1} K_{s 2}}{V_{1} K_{s 2}}+ \\
& +\frac{\frac{\left(V_{2}-V_{1}\right) V_{1} K_{s 2}-\left(V_{2} K_{s 1}-V_{1} K_{s 2}\right) V_{1}}{\mathrm{~V}_{1}^{2} K_{s 2}}[\mathrm{~S}]}{K_{s 2}+[\mathrm{S}]}
\end{aligned}
$$

$$
\begin{aligned}
& \frac{V_{\mu}}{v_{x o}}=\frac{V_{2} K_{s 1}-V_{1} K_{s 2}}{V_{1} K_{s 2}}+ \\
& +\frac{\frac{V_{2}\left(K_{s 2}-K_{s 1}\right)}{\mathrm{V}_{1} K_{s 2}}[\mathrm{~S}]}{K_{s 2}+[\mathrm{S}]}
\end{aligned}
$$


B5. Deduction of eqn. (18) from eqns.

(3) and (9) and the definition of $\varepsilon$.

$\varepsilon=\frac{\frac{V_{1} \alpha[\mathrm{S}]}{K_{s 1} \beta+[\mathrm{S}]}-\frac{V_{1}[\mathrm{~S}]}{K_{s 1}+[\mathrm{S}]}}{\frac{V_{1}[\mathrm{~S}]}{K_{s 1}+[\mathrm{S}]}}$

$\varepsilon=\frac{\alpha-\beta}{\beta}+\frac{\frac{(\alpha-1) K_{s 1} \beta-K_{s 1}(\alpha-\beta)}{K_{s l} \beta}[\mathrm{S}]}{K_{s 1} \beta+[\mathrm{S}]}$

$=\frac{\alpha-\beta}{\beta}+\frac{\frac{\alpha}{\beta}(\beta-1)[\mathrm{S}]}{K_{s i} \beta+[\mathrm{S}]}$

where

$=\frac{\frac{V_{2}-V_{1}}{V_{1}}[\mathrm{X}]-\frac{K_{s 2}-K_{s 1}}{K_{s 1}}[\mathrm{X}]}{K_{x 2}+[\mathrm{X}]+\frac{K_{s 2}-K_{s 1}}{K_{s 1}}[\mathrm{X}]}+$

$\alpha=1+\frac{\frac{V_{2}-V_{1}}{V_{1}}[\mathrm{X}]}{K_{x 2}+[\mathrm{X}]}$

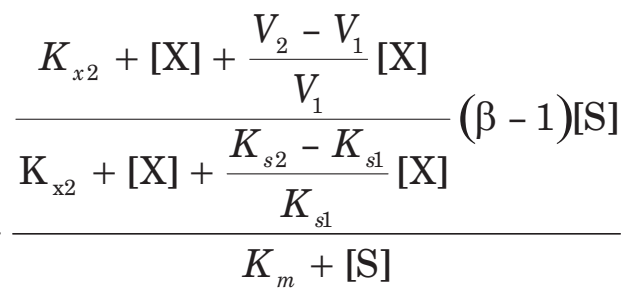

$\varepsilon=\frac{V_{1} \alpha[\mathrm{S}]\left(K_{s 1}+[\mathrm{S}]\right)-V_{1}[\mathrm{~S}]\left(K_{s l} \beta+[\mathrm{S}]\right)}{\mathrm{V}_{1}[\mathrm{~S}]\left(K_{s 1} \beta+[\mathrm{S}]\right)}$

$=\frac{\left(V_{2} K_{s 1}-V_{1} K_{s 2}\right)[\mathrm{X}]}{\mathrm{V}_{1} K_{s 1} K_{x 2}+V_{1} K_{s 2}[\mathrm{X}]}+$

$=\frac{(\alpha-\beta) K_{\mathrm{s} 1}+(\alpha-1)[\mathrm{S}]}{K_{s 1} \beta+[\mathrm{S}]}$

and, using the mathematical procedure described in the companion paper [17]:

$$
\begin{aligned}
& \frac{K_{x 2}+\frac{V_{2}}{V_{1}}[\mathrm{X}]}{K_{x 2}+\frac{K_{s 2}}{K_{s 1}}[\mathrm{X}]} K_{m}+[\mathrm{S}] \\
+ & \frac{\frac{V_{2} K_{s 1}-V_{1} K_{s 2}}{V_{1} K_{s 2}}[\mathrm{X}]}{K_{x 1}+[\mathrm{X}]}+ \\
\varepsilon & \left(\frac{\frac{K_{s 2}-K_{s 1}}{K_{s 1}}[\mathrm{X}]}{K_{x 2}+[\mathrm{X}]}\right)\left(\frac{K_{x 2}+\frac{V_{2}}{V_{1}}[\mathrm{X}]}{K_{x 2}+\frac{K_{s 2}}{K_{s 1}}[\mathrm{X}]}\right)[\mathrm{S}] \\
+ & \frac{K_{m}+[\mathrm{S}]}{}
\end{aligned}
$$




\section{R E F E R E N C E S}

1. Segel, I.H. (1975; reprinted 1993) Enzyme Kinetics. John Wiley \& Sons, New York.

2. Dixon, M. \& Weeb, E.C. (1979) Enzymes, 3rd Edn., Longman, London.

3. Fersht, A. (1985) Enzyme Structure and Mechanism, 2nd Edn., Fremann, New York.

4. Palmer, T. (1991) Understanding Enzymes, 3rd Edn., Ellis Horwood, New York.

5. Cornish-Bowden, A. (1995) Fundamentals of Enzyme Kinetics, Portland Press, London.

6. Cleland, W.W. (1970) Steady state kinetics; in The Enzymes, 3rd Edn. (Boyer, P.D., ed.) vol. 2, pp. 1-65, Academic Press, New York.

7. Sandler, M. \& Smith, H.J. (1989) Introduction to the use of enzyme inhibitors as drugs; in Design of Enzyme Inhibitors as Drugs (Sandler, M. \& Smith, H.J., eds.) pp. 1-18, Oxford University Press, Oxford.

8. Botts, J. \& Morales, M. (1953) Analytical description of the effects of modifiers and of enzyme multivalency upon the steady state catalyzed reaction rate. Trans. Faraday Soc. 49, 696-707.

9. Mahler, H.R. \& Cordes, E.H. (1966) Biological Chemistry, Harper \& Row, New York.

10. Ricard, J. (1973) Cinétique et mécanismes d'action des enzymes, Doin, Paris.
11. Metzler, D.E. (1977) Biochemistry, Academic Press, New York.

12. Mathews, C.K. \& van Holde, K.E. (1996) Biochemistry, 2nd Edn., Benjamin/Cummings, Redwood City (California).

13. Ribeiro, J.M., Juzgado, D., Crespo, E. \& Sillero, A. (1990) Computer program for the reservoir model of metabolic crossroads. Comput. Biol. Med. 20, 35-46.

14. Ribeiro, J.M., Fontes, R. \& Sillero, A. (1994) Enzyme inhibition as visualized with the reservoir model: relationships between $\mathrm{I}_{50}$ and inhibition constant(s) of an enzyme inhibitor. Comput. Biol. Med. 24, 129-144.

15. Fontes, R., Ribeiro, J.M. \& Sillero, A. (1994) A tridimensional representation of enzyme inhibition useful for diagnostic purposes. $J$. Enzym. Inhib. 8, 73-85.

16. Frieden, C. (1964) Treatment of enzyme kinetic data. I. The effect of modifiers on the kinetic parameters of single substrate enzymes. J. Biol. Chem. 239, 3522-3531.

17. Fontes, R., Ribeiro, J.M. \& Sillero, A. (1999) An easy procedure to transform the ratio of two polynomials of first degree into Michaelis-Menten-type equations. Application to the ordered Uni Bi enzyme mechanism. Acta Biochim. Polon. 47, 259-268. 